Review Article

\title{
High-Intensity Interval Training versus Moderate-Intensity Continuous Training on Health Outcomes for Children and Adolescents: A Meta-analysis of Randomized Controlled Trials
}

\author{
Jun Yin, Zhixiong Zhou $\mathbb{D}^{\mathrm{D}}$, and Tianwen Lan \\ Institute for Sport Performance and Health Promotion, Capital University of Physical Education and Sports, Beijing, China \\ Correspondence should be addressed to Zhixiong Zhou; zhouzhixiong@cupes.edu.cn
}

Received 20 April 2020; Revised 5 June 2020; Accepted 8 June 2020; Published 24 September 2020

Guest Editor: You Fu

Copyright ( 2020 Jun Yin et al. This is an open access article distributed under the Creative Commons Attribution License, which permits unrestricted use, distribution, and reproduction in any medium, provided the original work is properly cited.

\begin{abstract}
Low cardiorespiratory fitness (CRF) is considered as an established risk factor for cardiovascular and metabolic disorders. However, the effectiveness of high-intensity interval training (HIIT) versus moderate-intensity continuous training (MICT) in children and adolescents remained uncertain. Electronic databases of the PubMed, EmBase, and the Cochrane library were searched for randomized controlled trials (RCTs) investigated the role of HIIT versus MICT for children and adolescents throughout December 2019. Sixteen RCTs involving a total of 543 children were selected for final meta-analysis. HIIT versus MICT showed high peak $\mathrm{VO}_{2}$ (weighted mean differences (WMD): 2.68; 95\% confidence intervals (CIs): 1.81 to $3.55 ; P<0.001$ ), and no evidence of heterogeneity and publication bias was detected. However, there were no significant differences detected between HIIT and MICT on the levels of peak heart rate $\left(\mathrm{HR}_{\max }\right)$, fat mass, free fat mass, weight, body mass index, waist circumference, systolic blood pressure, diastolic blood pressure, glycemia, insulinemia, total cholesterol, high density lipoprotein, low density lipoprotein, triglycerides, HOMA-IR, HbA1c, and leptinemia. The findings of this study revealed that HIIT versus MICT showed a significant improvement in peak $\mathrm{VO}_{2}$ in children and adolescents. Further large-scale RCTs should be conducted to compare the long-term effects of HIIT versus MICT in children and adolescents.
\end{abstract}

\section{Introduction}

Cardiorespiratory fitness (CRF) is an objective reproducible physiological response that is affected by physical activity habits, genetics, and disease status [1]. Low CRF in subjects is identified as a risk factor of cardiovascular morbidity and mortality [2]. Currently, the gold standard for CRF included maximal oxygen uptake, which is measured directly or indirectly by maximal graded cardiorespiratory test [3-5]. According to a study, high CRF during childhood and adolescence showed association with reduced risk of subsequent cardiovascular disease [6]. A study involving 25.4 million children and adolescents from 27 countries with CRF showed declination by $3.6 \%$ per decade [5]. Regular physical activity could improve CRF [7] and whether different types of physical activity yields differential effects on CRF and other cardiovascular risk factors in children and adolescents remains controversial.
Although the high-intensity interval training (HIIT) was completed within a shorter time, it increased aerobic fitness and mental health in children [8-10]. Children in schools require effective exercise programs to improve their physical fitness and spend shorter time to exercise in schools [11]. Recently, several studies have already compared the effects of HIIT versus moderate-intensity continuous training (MICT) on the outcomes of body mass index (BMI), hypertension, endothelial function, prediabetes, and type 2 diabetes in adults [12-15]. Moreover, the CRF, fat loss, and cardiometabolic health between HIIT and MICT in children and adolescents were compared, and various role of HIIT and MICT could explain by mitochondrial adaptations to short-term training $[16,17]$. Numerous studies have already been conducted to compare the effects of HIIT versus MICT in children and adolescents, which can enter into pooled analysis to reevaluate the effectiveness of HIIT versus MICT. Therefore, the current systematic review and meta-analysis 
was conducted on randomized controlled trials (RCTs) that compared the effects of HIIT versus MICT on the health outcomes of children and adolescents.

\section{Materials and Methods}

2.1. Data Sources, Search Strategy, and Selection Criteria. The Preferred Reporting Items for Systematic Reviews and MetaAnalysis (PRISMA) Statement was applied to guide the reporting of this systematic review [18]. Studies designed as RCT that compared the effects of HIIT versus MICT in children and adolescents were considered eligible in our study, and there is no restriction to publication language and status. The core search terms of (high intensity interval OR highintensity interval OR high intensity intermittent OR highintensity intermittent OR sprint interval OR HIIT OR HIIE) AND (children [MeSH] OR *adolescent [MeSH] OR boy OR girl OR youth [MeSH] OR kids OR student*) AND (randomized controlled trials) were employed to search for potential trials from the PubMed, EmBase, and Cochrane Library electronic databases throughout December 2019. The reference lists from the retrieved studies were also reviewed manually to identify for studies that met the inclusion criteria.

Two authors independently conducted the literature search and study selection processes, and any disagreements were settled by group discussion until a consensus was reached. The details regarding the inclusion criteria are as follows: (1) participants: the mean age of children or adolescents < 18.0 years; (2) intervention: HIIT; (3) control: MICT; (4) outcomes: peak oxygen uptake $\left(\mathrm{VO}_{2}\right), \mathrm{HR}_{\max }$, fat mass, free fat mass, weight, BMI, WC, systolic blood pressure (SBP), diastolic blood pressure (DBP), glycemia, insulinemia, total cholesterol (TC), high density lipoprotein (HDL), low density lipoprotein (LDL), triglycerides (TG), HOMA-IR, HbAlc, and leptinemia; and (5) study design: RCT. Study with observational design was excluded owing to confounding variables or bias.

2.2. Data Collection and Quality Assessment. The data abstraction and quality evaluation from the retrieved studies were conducted by 2 authors independently, and any conflicts were resolved by group discussion. The data collected included the first author's surname, publication year, country, sample size, mean age, percentage male, intervention, control, follow-up duration, and reported outcomes. The Jadad scale was used to assess the quality of included trials, which is based on the following 5 subscales: randomization, concealment of treatment allocation, blinding, completeness of follow-up, and use of intention-to-treat analysis [19]. In this study, the trials that scored 4 or 5 were considered as high quality.

2.3. Statistical Analysis. The effects of HIIT versus MICT on health outcomes in children and adolescents were included as continuous data, and the weighted mean differences (WMDs) with 95\% confidence intervals (CIs) were calculated before data pooling. The random-effects models were used to calculate the pooled effect estimates owing to it considering the underlying varies across included studies [20, 21]. The heterogeneity across included trials were assessed using $I^{2}$ and $Q$ statistics, and significant heterogeneity was defined as $I^{2}>50.0 \%$ or $P<0.10[22,23]$. The stability of pooled conclusions was then assessed by a sensitivity analysis [24]. Subgroup analyses of investigated outcomes were conducted based on the mean age of subjects, and the differences between subgroups were assessed by interaction $P$ test [25]. Publication biases for investigated outcomes were assessed by using the funnel plots, Egger, and Begg tests [26, 27]. The inspection levels for pooled results are two-sided, and $P<0.05$ was considered as statistically significant difference between HIIT and MICT. The data in this meta-analysis was analyzed by using the STATA software (version 12.0; Stata Corporation, College Station, TX, USA).

\section{Results}

3.1. Literature Search. A total of 1,846 articles were identified by initial electronic search, and 1,055 articles of these were excluded owing to duplications. Next, 730 articles were further excluded because of irrelevant topics. Full-text evaluations were done for the remaining 61 studies, and 45 studies were excluded because of the following reasons: no appropriate control $(n=33)$, no desirable outcomes $(n=6)$, and no RCT design $(n=6)$. After this, a total of 16 RCTs were considered eligible and included in the final meta-analysis [28-43]. No new eligible trial was identified by manual searching of the reference lists of retrieved studies (Figure 1). The baseline characteristics of the included trials are summarized in Table 1.

3.2. Study Characteristics. A total of 543 children were included in the trials that are published from 2005 to 2019. The follow-up duration ranged from 3.0 to 24.0 weeks, and 13-94 children were included in each individual trial. Thirteen RCTs were conducted in Western countries or Africa, and the remaining 3 were conducted in Asia. The mean age of children and adolescents included in the trials ranged from 8.2 to 17.4 years, and 4 trials included only boys. The Jadad scale was used to assess the study quality, in which 5 trials had a score of 4,7 trials scored 3,3 trials scored 2, and the remaining 1 trial scored 1 .

3.3. Peak $\mathrm{VO}_{2}$. The data regarding the effect of HIIT versus MICT on peak $\mathrm{VO}_{2}$ were available in 10 trials. The peak $\mathrm{VO}_{2}$ was significantly higher in the HIIT group (WMD: 2.68; 95\% CI: 1.81 to 3.55; $P<0.001$; Figure 2), and no heterogeneity was detected across the included trials $\left(I^{2}=0.0 \%\right.$ ; $P=0.460)$. The conclusion was robust and unchanged by sequential exclusion of each individual trial (Supplemental 1 and Supplemental 3). Subgroup analysis showed significant differences between HIIT and MICT in peak $\mathrm{VO}_{2}$ in children $\geq 12.0$ years (Table 2 ). No significant publication bias for peak $\mathrm{VO}_{2}$ was detected ( $P$ value for Egger: 0.339; $P$ value for Begg: 0.213; Supplemental 2).

3.4. Peak Heart Rate. The data regarding the effect of HIIT versus MICT on $\mathrm{HR}_{\max }$ were available in 7 trials. No significant difference between HIIT and MICT for $\mathrm{HR}_{\max }$ was 


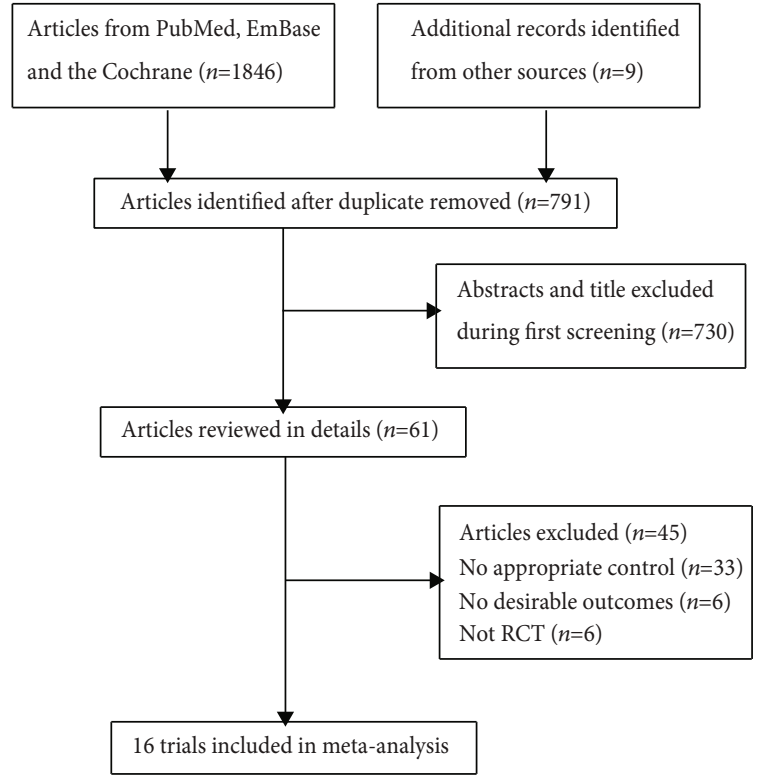

FIGURE 1: Flow diagram of literature search and trial selection process.

detected (WMD: $0.35 ; 95 \% \mathrm{CI}:-3.90$ to $4.60 ; P=0.872$; Figure 3), and significant heterogeneity was detected among the included trials $\left(I^{2}=83.7 \% ; P<0.001\right)$. Sensitivity analysis found a stable conclusion and was unaltered by sequential exclusion of individual trial (Supplemental 1 and Supplemental 3). Subgroup analysis suggested that HIIT was associated with lower $\mathrm{HR}_{\max }$ if the mean age of children was $<12.0$ years (Table 2). No significant publication bias was observed for $\mathrm{HR}_{\max }(P$ value for Egger: 0.596; $P$ value for Begg: 1.000; Supplemental 2).

3.5. Fat Mass. The data regarding the effect of HIIT versus MICT on fat mass were available from 11 trials. There were no significant differences between HIIT and MICT for fat mass (WMD: -0.15 ; $95 \% \mathrm{CI}:-1.85$ to $1.55 ; \quad P=0.863$; Figure 4 ), and similarly, no potential significant heterogeneity across the included trials was observed $\left(I^{2}=48.7 \% ; P=\right.$ $0.034)$. The conclusion was robust and unaltered by sequential exclusion of individual trials (Supplemental 1 and Supplemental 3). The results of subgroup analyses were consistent with the overall analysis (Table 2). Although the Begg test indicated no significant publication bias, the Egger test showed potentially significant publication bias for fat mass ( $P$ value for Egger: 0.019; $P$ value for Begg: 0.350; Supplemental 2). The conclusion was changed when the trim and fill method was used to adjust potential publication bias (Supplemental 2).

3.6. Free Fat Mass. The data regarding the effect of HIIT versus MICT on free fat mass were available in 4 trials. HIIT showed no significant effect on free fat mass when compared with MICT (WMD: 0.38; 95\% CI: -2.32 to 3.09; $P=0.781$; Figure 5), and no evidence of heterogeneity was observed $\left(I^{2}=0.0 \% ; P=0.920\right)$. The conclusion remained robust after reviewing the results of sensitivity analysis (Supplemental 1 and Supplemental 3). The conclusions of subgroup analyses were consistent with that of overall analysis (Table 2). There was no significant publication bias for free fat mass ( $P$ value for Egger: 0.345; $P$ value for Begg: 0.308; Supplemental 2).

3.7. Weight. The data regarding the effect of HIIT versus MICT on weight were available from 11 trials, and no significant differences between HIIT and MICT for weight were observed (WMD: -0.46 ; $95 \% \mathrm{CI}$ : -2.29 to $1.37 ; P=0.623$; Figure 6). Moreover, unimportant heterogeneity was detected for weight $\left(I^{2}=13.5 \% ; P=0.312\right)$. Sensitivity analysis revealed robust conclusion and showed nonsignificant difference by sequentially excluding each trial (Supplemental 1 and Supplemental 3). Subgroup analyses suggested that the conclusions were consistent with the overall analysis in all subsets (Table 2). No significant publication bias for weight was detected ( $P$ value for Egger: 0.600; $P$ value for Begg: 0.631; Supplemental 2).

3.8. Body Mass Index. The data regarding the effect of HIIT versus MICT on BMI were available from 13 trials. The pooled results suggested that HIIT demonstrated no significant effect on BMI when compared with MICT (WMD: -0.01 ; $95 \%$ CI: -0.62 to $0.60 ; P=0.978$; Figure 7 ), and unimportant heterogeneity was detected $\left(I^{2}=19.9 \% ; P=0.237\right)$. Sensitivity analysis suggested that the conclusion remained unchanged by sequential exclusion of each trial (Supplemental 1 and Supplemental 3). Moreover, the results of subgroup analyses were consistent with that of the overall analysis in all subsets (Table 2). No significant publication bias was observed for BMI ( $P$ value for Egger: 0.775; $P$ value for Begg: 0.743; Supplemental 2).

3.9. Waist Circumference. The data regarding the effect of HIIT versus MICT on WC were available in 6 trials. There was no significant difference between HIIT and MICT on WC (WMD: $-1.47 ; 95 \%$ CI: -4.67 to $1.73 ; P=0.369$; Figure 8 ), and significant heterogeneity was seen for WC $\left(I^{2}=63.4 \% ; P=0.018\right)$. The conclusion remains stable and unaltered by sequentially excluding each trial (Supplemental 1 and Supplemental 3). No significant difference was observed between HIIT and MICT in subgroup analysis (Table 2). There was no significant publication bias detected for WC ( $P$ value for Egger: 0.443; $P$ value for Begg: 1.000; Supplemental 2).

3.10. Systolic Blood Pressure. The data regarding the effect of HIIT versus MICT on SBP were available in 7 trials. The results revealed that HIIT has no significant effect on SBP when compared with MICT (WMD: -1.36 ; 95\% CI: -3.99 to 1.27; $P=0.311$; Figure 9), and significant heterogeneity was detected $\left(I^{2}=65.1 \% ; P=0.005\right)$. The results of sensitivity analysis suggested that the conclusion was robust and unaltered by sequentially excluding individual trial (Supplemental 1 and Supplemental 3). The results of subgroup analyses showed no significant differences between HIIT and MICT on SBP in all subsets (Table 2). No significant publication bias was observed for SBP ( $P$ value for Egger: 0.266 ; $P$ value for Begg: 1.000; Supplemental 2). 
TABLE 1: The baseline characteristics of included studies.

\begin{tabular}{|c|c|c|c|c|c|c|c|c|}
\hline Study & Country & $\begin{array}{c}\text { Sample } \\
\text { size }\end{array}$ & $\begin{array}{l}\text { Mean } \\
\text { age } \\
\text { (years) }\end{array}$ & $\begin{array}{c}\text { Percentage } \\
\text { male }(\%)\end{array}$ & Intervention & Control & $\begin{array}{c}\text { Follow- } \\
\text { up }\end{array}$ & $\begin{array}{c}\text { JADAD } \\
\text { scale }\end{array}$ \\
\hline $\begin{array}{l}\text { McManus } \\
2005 \text { [28] }\end{array}$ & China & 20 & 10.4 & 100.0 & $\begin{array}{l}\text { Seven maximal speed sprints } \\
\text { for } 30 \mathrm{~s} \text { should be completed } \\
\text { during a } 20 \text {-minute session, } \\
\text { with a load set at the power } \\
\text { elicited at peak } \mathrm{VO}_{2} \text {. Between } \\
\text { each sprint, an active unloaded } \\
\text { rest bout of } 2 \text { minutes } 45 \mathrm{~s} \\
\text { cycling was allowed }\end{array}$ & $\begin{array}{l}\text { 20-minute sessions of } \\
\text { continuous cycling period with } \\
\text { a heart rate between } 160 \text { and } \\
170 \text { beats per minute. This is } \\
\text { equated to a mean intensity of } \\
75-85 \% \text { peak } \mathrm{VO}_{2} \text { or } 85 \% \\
\mathrm{HR}_{\text {max }} \text {, as established in the } \\
\text { pretraining peak } \mathrm{VO}_{2} \text { test }\end{array}$ & 8 weeks & 2 \\
\hline $\begin{array}{l}\text { Corte de } \\
\text { Araujo } \\
2012[29]\end{array}$ & Brazil & 30 & 10.6 & 30.0 & $\begin{array}{l}\text { Repeated } 60 \text {-second efforts } \\
\text { (covered distance per bout: } \\
118 \pm 14.5 \mathrm{~m} \text { ) at } 100 \% \text { of the } \\
\text { peak velocity (determined by } \\
\text { the maximal graded } \\
\text { cardiorespiratory test), } \\
\text { interspersed by a } 3 \text { min active } \\
\text { recovery period at } 50 \% \text { of the } \\
\text { peak velocity }\end{array}$ & $\begin{array}{l}\text { 30-minute continuous } \\
\text { endurance exercise at } 80 \% \text { of } \\
\text { the peak HR }\end{array}$ & $\begin{array}{c}12 \\
\text { weeks }\end{array}$ & 3 \\
\hline $\begin{array}{l}\text { Koubaa } \\
2013[30]\end{array}$ & Tunisia & 29 & 12.9 & 100.0 & $\begin{array}{c}\text { Run for } 2 \text { min interspersed } \\
\text { with recovery periods of one } \\
\text { minute. The exercise intensity } \\
\text { was } 80 \% \text { of the } \mathrm{vVO}_{2} \text { max } \\
\text { increased by } 5 \% \text { every four } \\
\text { weeks }\end{array}$ & $\begin{array}{c}\text { Continuously at } 60 \% \text { of } \mathrm{vVO}_{2} \\
\max \text { (first } 4 \text { weeks), } 65 \% \text { of } \\
\mathrm{vVO}_{2} \max (\text { second } 4 \text { weeks), } \\
\text { and } 70 \% \text { of } \mathrm{vVO}_{2} \max (3 \mathrm{rd} 4 \\
\text { weeks) }\end{array}$ & $\begin{array}{c}12 \\
\text { weeks }\end{array}$ & 1 \\
\hline $\begin{array}{l}\text { Boer } 2014 \\
{[31]}\end{array}$ & Belgium & 32 & 17.4 & 65.6 & $\begin{array}{l}\text { Warm-up (stretching of the } \\
\text { large muscle groups and } \\
\text { cardiovascular exercises at } 30 \% \\
\text { of peak watt for five minutes), a } \\
\text { sprint interval block ( } 10 \\
\text { minutes), continuous aerobic } \\
\text { exercise (10 minutes), another } \\
\text { sprint interval block ( } 10 \\
\text { minutes), and cooling down } \\
\text { (stretching of the large muscle } \\
\text { groups and cardiovascular } \\
\text { exercises at } 30 \% \text { of peak watt } \\
\text { for } 5 \text { minutes) }\end{array}$ & $\begin{array}{l}\text { Warming up (stretching of the } \\
\text { large muscle groups and } \\
\text { cardiovascular exercises at } 30 \% \\
\text { of peak watt for five minutes), } \\
\text { cycling (10 minutes), } \\
\text { walking/running ( } 10 \text { minutes), } \\
\text { stepping (10 minutes), and } \\
\text { cooling down (stretching of the } \\
\text { large muscle groups and } \\
\text { cardiovascular exercises at } 30 \% \\
\text { of peak watt for five minutes) }\end{array}$ & $\begin{array}{c}15 \\
\text { weeks }\end{array}$ & 2 \\
\hline $\begin{array}{l}\text { Farah } 2014 \\
\text { [32] }\end{array}$ & Brazil & 19 & 15.0 & 52.6 & $\begin{array}{l}\text { Personalized aerobic training } \\
\text { on a treadmill, three times a } \\
\text { week under the supervision of } \\
\text { an exercise physiologist at an } \\
\text { intensity that corresponds to } \\
\text { the ventilatory threshold I }\end{array}$ & $\begin{array}{l}\text { Personalized aerobic training } \\
\text { on a treadmill three times a } \\
\text { week under the supervision of } \\
\text { an exercise physiologist at a } \\
\text { speed of } 20 \% \text { below the } \\
\text { ventilatory threshold I }\end{array}$ & $\begin{array}{c}24 \\
\text { weeks }\end{array}$ & 3 \\
\hline $\begin{array}{l}\text { Starkoff } \\
2014 \text { [33] }\end{array}$ & USA & 27 & 14.7 & 37.0 & $\begin{array}{c}10 \text {, two-minute cycling bouts } \\
\text { at } 90-95 \% \text { of age as predicted } \\
\text { by } \mathrm{HR}_{\max } \text {, with one minute of } \\
\text { active recovery at } 55 \% \text { of age } \\
\text { predicted by } \mathrm{HR}_{\max } \text { between } \\
\text { each interval for a total of } 30 \\
\text { minutes }\end{array}$ & $\begin{array}{l}\text { Cycle at any speed and } \\
\text { workload as long as they stayed } \\
\text { within the specified target HR } \\
\text { range. Following the warm-up, } \\
\text { cycling was continuously done } \\
\text { for } 30 \text { minutes at } 65-70 \% \text { of } \\
\text { age predicted } \mathrm{HR}_{\max }\end{array}$ & 6 weeks & 3 \\
\hline $\begin{array}{l}\text { Murphy } \\
2015 \text { [34] }\end{array}$ & USA & 13 & 14.0 & 23.1 & $\begin{array}{l}\text { A } 10 \text {-minute warm-up, } \\
\text { followed by } 30 \text { minutes of } 10 \\
\text { cycles of vigorous exercise at } \\
80 \text { to } 90 \% \mathrm{HR}_{\max }, 2 \text { minutes of } \\
\text { active recovery at } 60 \% \mathrm{HR}_{\max } \\
\text { and } 10 \text { minutes of cooldown }\end{array}$ & $\begin{array}{l}50 \text { minutes of supervised } \\
\text { aerobic exercise with a regimen } \\
\text { consisting of a } 10 \text {-minute } \\
\text { warm-up, } 30 \text { minutes of } \\
\text { relatively continuous aerobic } \\
\text { exercise at } 65 \% \text { of estimated }\end{array}$ & 4 weeks & 2 \\
\hline
\end{tabular}


TABle 1: Continued.

\begin{tabular}{|c|c|c|c|c|c|c|c|c|}
\hline Study & Country & $\begin{array}{l}\text { Sample } \\
\text { size }\end{array}$ & $\begin{array}{l}\text { Mean } \\
\text { age } \\
\text { (years) }\end{array}$ & $\begin{array}{c}\text { Percentage } \\
\text { male }(\%)\end{array}$ & Intervention & Control & $\begin{array}{c}\text { Follow- } \\
\text { up }\end{array}$ & $\begin{array}{c}\text { JADAD } \\
\text { scale }\end{array}$ \\
\hline & & & & & & $\begin{array}{l}\text { exercise capacity, and a } 10- \\
\text { minute cooldown period }\end{array}$ & & \\
\hline $\begin{array}{l}\text { Lee } 2015 \\
{[35]}\end{array}$ & Korea & 20 & 15.3 & NA & $\begin{array}{l}\text { Supervised high-intensity } \\
\text { interval exercise ( } 30 \text { s sprint, } \\
30 \text { s recovery) continuously } \\
\text { throughout the session, which } \\
\text { burns } 400 \mathrm{kcal}\end{array}$ & $\begin{array}{c}\text { Supervised exercise on a } \\
\text { treadmill six times weekly for } \\
12 \text { weeks at } \leq 40 \% \text { HR reserve } \\
\text { ( } 6 \text { days/week })\end{array}$ & $\begin{array}{c}12 \\
\text { weeks }\end{array}$ & 3 \\
\hline $\begin{array}{l}\text { Kargarfard } \\
2016 \text { [36] }\end{array}$ & Iran & 40 & 12.3 & NA & $\begin{array}{l}50-60 \text { min of continuous } \\
\text { running starting at a work rate } \\
\text { corresponding to } 60-70 \% \text { of } \\
\text { HR reserve in the first week } \\
\text { and then progressively } \\
\text { increasing to } 80-90 \% \text { heart rate } \\
\text { reserve throughout the } \\
\text { intervention period }\end{array}$ & $\begin{array}{l}50-60 \text { minutes of continuous } \\
\text { running on a treadmill } \\
\text { beginning in the first week at a } \\
\text { work rate of } 60-70 \% \text { of HR } \\
\text { reserve and then progressively } \\
\text { increasing to } 80-95 \% \mathrm{HR} \\
\text { reserve throughout the } \\
\text { intervention period }\end{array}$ & 8 weeks & 4 \\
\hline $\begin{array}{l}\text { Martínez } \\
2016 \text { [37] }\end{array}$ & Spain & 94 & 8.2 & 55.3 & $\begin{array}{l}2 \text { sessions of } 40 \text {-minute } \\
\text { duration per week. Each } \\
\text { session involved } 20 \text { minutes of } \\
\text { high-intensity intermittent } \\
\text { exercises (around } 10-20 \text { s) and } \\
20 \text { minutes of sports activities }\end{array}$ & $\begin{array}{l}2 \text { sessions of } 40 \text {-minute } \\
\text { duration per week. Each } \\
\text { session involved } 20 \text { minutes of } \\
\text { high-intensity intermittent } \\
\text { exercises (around } 10-20 \mathrm{~s} \text { ) and } \\
20 \text { minutes of sports activities }\end{array}$ & $\begin{array}{c}12 \\
\text { weeks }\end{array}$ & 3 \\
\hline $\begin{array}{l}\text { Lazzer } \\
2017 \text { [38] }\end{array}$ & Italy & 30 & 16.5 & 100.0 & $\begin{array}{l}6 \text { repeated } 40 \mathrm{~s} \text { efforts of high- } \\
\text { intensity walking at a heart rate } \\
\text { that corresponds to } 100 \% \text { of } \\
\mathrm{VO}_{2} \text { max and then were } \\
\text { intermixed with } 5 \text { min of } \\
\text { walking at low intensity } \\
\text { corresponding to } 40 \% \text { of } \mathrm{VO}_{2} \\
\max \end{array}$ & $\begin{array}{l}\text { Exercising at a } \mathrm{HR} \text { that } \\
\text { corresponds to } 40 \% \text { or } 70 \% \text { of } \\
\mathrm{VO}_{2} \max \end{array}$ & 3 weeks & 4 \\
\hline $\begin{array}{l}\text { Dias } 2018 \\
\text { [39] }\end{array}$ & Australia & 65 & 12.2 & 66.0 & $\begin{array}{l}\text { Three times each week for } 12 \\
\text { weeks and all participants } \\
\text { received between four and six, } \\
20 \text { - } 30 \text { min nutrition } \\
\text { consultations with a dietitian } \\
\text { for over } 12 \text {-week period }\end{array}$ & $\begin{array}{l}\text { Three times each week for } 12 \\
\text { weeks and all participants } \\
\text { received between four and six, } \\
20 \text { - } 30 \text { min nutrition } \\
\text { consultations with a dietitian } \\
\text { for over } 12 \text {-week period }\end{array}$ & $\begin{array}{c}12 \\
\text { weeks }\end{array}$ & 4 \\
\hline $\begin{array}{l}\text { van Biljon } \\
2018 \text { [40] }\end{array}$ & $\begin{array}{l}\text { South } \\
\text { Africa }\end{array}$ & 58 & 11.1 & 44.8 & $\begin{array}{l}10 \text { intervals of } 1 \text {-minute } \\
\text { sprinting set at }>80 \% \text { of their } \\
\text { predicted } \mathrm{HR}_{\max }\end{array}$ & $\begin{array}{c}33 \text { minutes of continuous brisk } \\
\text { walking at an intensity level set } \\
\text { at } 65 \%-70 \% \text { of their predicted } \\
\mathrm{HR}_{\max }\end{array}$ & 5 weeks & 3 \\
\hline $\begin{array}{l}\text { Morrissey } \\
2018 \text { [41] }\end{array}$ & France & 29 & 15.0 & 27.6 & $\begin{array}{c}(4 \text { to } 6) *(2 \min \text { to } 2 \min 30 \mathrm{~s}) \\
\text { periods at } 90-95 \% \text { of } \mathrm{HR}_{\max } \\
\text { interspersed by } 1 \min 30 \mathrm{~s} \\
\text { periods at } 55 \% \text { of } \mathrm{HR}_{\max }\end{array}$ & $\begin{array}{c}40 \text { min at } 60 \% \text { of } \mathrm{HR}_{\max } \\
\text { progressing to } 60 \text { min at } 65- \\
70 \% \text { of } \mathrm{HR}_{\max }\end{array}$ & $\begin{array}{c}12 \\
\text { weeks }\end{array}$ & 3 \\
\hline $\begin{array}{l}\text { Cvetković } \\
2018 \text { [42] }\end{array}$ & Serbia & 21 & $\begin{array}{c}11.0- \\
13.0\end{array}$ & 100.0 & $\begin{array}{l}\text { Three sets of high-intensity } \\
\text { interval run separated by } 3 \\
\text { minutes of passive rest, 10- } \\
\text { minute warm-up protocol } \\
\text { followed by high-intensity } \\
\text { interval runs and ended with a } \\
\text { 10-minute cooldown (warm- } \\
\text { up protocol and cooldown } \\
\text { were the same as the football } \\
\text { training group) }\end{array}$ & $\begin{array}{l}\text { A } 10 \text {-minute low intensity } \\
\text { warm-up followed by } 4^{*} 8 \text { - } \\
\text { minute periods of play } \\
\text { interspersed with } 2 \text { minutes of } \\
\text { passive rest and ending with a } \\
\text { 10-minute cooldown }\end{array}$ & $\begin{array}{c}12 \\
\text { weeks }\end{array}$ & 4 \\
\hline $\begin{array}{l}\text { Nugent } \\
2019[43]\end{array}$ & UK & 16 & 15.8 & 37.5 & $\begin{array}{l}1 \text { hour }(2.8 \mathrm{~km}) \text { per session, } \\
\text { each session was divided into a }\end{array}$ & $\begin{array}{l}2 \text { hours }(5.6 \mathrm{~km}) \text { per session, } \\
\text { trained as normal, which }\end{array}$ & 7 weeks & 4 \\
\hline
\end{tabular}


TABLE 1: Continued.

\begin{tabular}{|c|c|c|c|c|c|c|c|c|}
\hline Study & Country & $\begin{array}{l}\text { Sample } \\
\text { size }\end{array}$ & $\begin{array}{l}\text { Mean } \\
\text { age } \\
\text { (years) }\end{array}$ & $\begin{array}{l}\text { Percentage } \\
\text { male }(\%)\end{array}$ & Intervention & Control & $\begin{array}{c}\text { Follow- } \\
\text { up }\end{array}$ & $\begin{array}{l}\text { JADAD } \\
\text { scale }\end{array}$ \\
\hline & & & & & $\begin{array}{l}\text { warm-up, main, and cooldown } \\
\text { sessions }\end{array}$ & $\begin{array}{c}\text { primarily involved zone } 1 \\
\text { training across }\end{array}$ & & \\
\hline
\end{tabular}

\begin{tabular}{|c|c|c|c|}
\hline Study & & $\begin{array}{l}\text { Mean difference } \\
(95 \% \mathrm{Cl})\end{array}$ & $\%$ weight \\
\hline McManus 2005 & & $0.00(-4.85,4.85)$ & 3.2 \\
\hline Koubaa 2013 & & $3.70(1.85,5.55)$ & 22.2 \\
\hline Boer 2014 & & $0.20(-3.84,4.24)$ & 4.6 \\
\hline Farah 2014 & & $3.60(1.47,5.73)$ & 16.7 \\
\hline Starkoff 2014 & & $3.10(-2.25,8.45)$ & 2.6 \\
\hline Murphy 2015 & & $2.50(-1.12,6.12)$ & 5.8 \\
\hline Kargarfard 2016 & & $0.77(-2.86,4.40)$ & 5.7 \\
\hline Kargarfard 2016 & & $1.08(-2.70,4.86)$ & 5.3 \\
\hline Martínez 2016 & & $1.90(0.08,3.72)$ & 22.9 \\
\hline Dias 2018 & & $3.00(-0.96,6.96)$ & 4.8 \\
\hline van Biljon 2018 & & $5.70(2.15,9.25)$ & 6.0 \\
\hline Overall & & $\begin{array}{l}2.68(1.81,3.55) ; P<0.001 \\
\left(I^{2}: 0.0 \% ; P=0.460\right)\end{array}$ & 100.0 \\
\hline-5 & 5 & & \\
\hline
\end{tabular}

FIGURE 2: Effect of high-intensity interval training versus moderate-intensity continuous training on peak $\mathrm{VO}_{2}$.

3.11. Diastolic Blood Pressure. The data regarding the effect of HIIT versus MICT on DBP were available in 7 trials. There was no significant difference detected between HIIT and MICT for DBP (WMD: 0.57 ; $95 \%$ CI: -0.55 to $1.69 ; P=$ 0.321 ; Figure 10), and no evidence of heterogeneity was seen $\left(I^{2}=0.0 \% ; P=0.681\right)$. The conclusion was robust and unaffected by sequential exclusion of individual trial (Supplemental 1 and Supplemental 3) and was stratified by the mean age (Table 2). No significant publication bias for DBP was observed ( $P$ value for Egger: 0.165; $P$ value for Begg: 0.174; Supplemental 2).

3.12. Glycemia. The data regarding the effect of HIIT versus MICT on glycemia were available in 4 trials. No significant difference between the groups for glycemia was observed (WMD: -2.14 ; $95 \% \mathrm{CI}$ : -7.62 to $3.35 ; P=0.445$; Figure 11 ), and potentially significant heterogeneity was detected $\left(I^{2}=64.3 \% ; P=0.038\right)$. The results of sensitivity analysis (Supplemental 1 and Supplemental 3) and subgroup analysis were consistent with that of the overall analysis (Table 2). No significant publication bias for glycemia was observed $(P$ value for Egger: 0.879; $P$ value for Begg: 0.734; Supplemental 2).

3.13. Insulinemia. The data regarding the effect of HIIT versus MICT on insulinemia were available in 6 trials. The results showed no significant effect of HIIT on insulinemia when compared with MICT (WMD: -1.72 ; 95\% CI: -4.13 to $0.69 ; P=0.163$; Figure 12 ), and no significant heterogeneity across the included trials was observed $\left(I^{2}=24.5 \% ; P=\right.$ 0.250 ). The results of sensitivity analysis (Supplemental 1 and Supplemental 3) and subgroup analysis were consistent with that of the overall analysis (Table 2). There was no significant publication bias for insulinemia $(P$ value for Egger: 0.359; $P$ value for Begg: 0.707; Supplemental 2).

3.14. Total Cholesterol. The data regarding the effect of HIIT versus MICT on TC were available in 5 trials. There was no significant difference between HIIT and MICT for TC (WMD: -6.22 ; 95\% CI: -12.87 to $0.42 ; P=0.066$; Figure 13 ), and no evidence of heterogeneity across included trials $\left(I^{2}=0.0 \% ; P=0.584\right)$. The results of sensitivity analysis (Supplemental 1 and Supplemental 3) and subgroup analysis were consistent with that of the overall analysis (Table 2). No significant publication bias was seen for TC $(P$ value for Egger: 0.894; $P$ value for Begg: 1.000; Supplemental 2).

3.15. High Density Lipoprotein. The data regarding the effect of HIIT versus MICT on HDL were available in 4 trials. HIIT showed no association with HDL when compared with MICT (WMD: 0.73 ; 95\% CI: -4.49 to $5.94 ; P=0.785$; Figure 14), but significant heterogeneity was observed $\left(I^{2}=72.5 \% ; P=0.012\right)$. The results of sensitivity analysis indicated that HIIT might be associated with low HDL (Supplemental 1 and Supplemental 3). Moreover, subgroup analysis found no significant difference between groups on HDL in all subsets (Table 2). There was no significant publication 
TABLE 2: Subgroup analyses of investigated outcomes based on age ( $\geq 12.0$ years and $<12.0$ years).

\begin{tabular}{|c|c|c|c|c|c|c|}
\hline Outcomes & Subgroup & Number of studies & WMD and $95 \%$ CI & $P$ value & $I^{2}(\%)$ & $P$ value between subgroups \\
\hline \multirow{2}{*}{ Peak $\mathrm{VO}_{2}$} & $\geq 12.0$ years & 7 & $2.81(1.75$ to 3.86$)$ & $<0.001$ & 0.0 & \multirow{2}{*}{0.685} \\
\hline & $<12.0$ years & 3 & $2.65(-0.17$ to 5.48$)$ & 0.066 & 55.9 & \\
\hline \multirow{2}{*}{ Peak heart rate } & $\geq 12.0$ years & 5 & $2.46(-3.11$ to 8.02$)$ & 0.387 & 87.8 & \multirow{2}{*}{0.046} \\
\hline & $<12.0$ years & 2 & $-4.36(-8.12$ to -0.61$)$ & 0.023 & 0.0 & \\
\hline \multirow{2}{*}{ Fat mass } & $\geq 12.0$ years & 9 & $-0.30(-2.31$ to 1.71$)$ & 0.771 & 55.1 & \multirow{2}{*}{0.258} \\
\hline & $<12.0$ years & 2 & $0.64(-2.23$ to 3.51$)$ & 0.660 & 0.0 & \\
\hline \multirow{2}{*}{ Free fat mass } & $\geq 12.0$ years & 3 & $0.54(-2.68$ to 3.76$)$ & 0.741 & 0.0 & \multirow{2}{*}{0.858} \\
\hline & $<12.0$ years & 1 & $0.00(-4.98$ to 4.98$)$ & 1.000 & - & \\
\hline \multirow{2}{*}{ Weight } & $\geq 12.0$ years & 9 & $-0.59(-2.73$ to 1.55$)$ & 0.591 & 20.8 & \multirow{2}{*}{0.736} \\
\hline & $<12.0$ years & 2 & $0.58(-4.92$ to 6.08$)$ & 0.836 & 19.0 & \\
\hline \multirow{2}{*}{ BMI } & $\geq 12.0$ years & 10 & $-0.05(-0.85$ to 0.75$)$ & 0.899 & 35.7 & \multirow{2}{*}{0.705} \\
\hline & $<12.0$ years & 3 & $0.15(-0.93$ to 1.24$)$ & 0.780 & 0.0 & \\
\hline \multirow{2}{*}{ Waist circumference } & $\geq 12.0$ years & 3 & $-2.44(-6.82$ to 1.94$)$ & 0.274 & 39.7 & \multirow{2}{*}{0.345} \\
\hline & $<12.0$ years & 3 & $-0.71(-5.86$ to 4.44$)$ & 0.786 & 78.9 & \\
\hline \multirow{2}{*}{ SBP } & $\geq 12.0$ years & 5 & $-1.32(-4.50$ to 1.87$)$ & 0.419 & 74.0 & \multirow{2}{*}{0.609} \\
\hline & $<12.0$ years & 2 & $-1.41(-5.82$ to 2.99$)$ & 0.529 & 0.0 & \\
\hline \multirow{2}{*}{ DBP } & $\geq 12.0$ years & 5 & $0.81(-0.45$ to 2.07$)$ & 0.208 & 0.0 & \multirow{2}{*}{0.410} \\
\hline & $<12.0$ years & 2 & $-0.35(-2.80$ to 2.11$)$ & 0.782 & 0.0 & \\
\hline \multirow{2}{*}{ Glycemia } & $\geq 12.0$ years & 3 & $-3.64(-12.38$ to 5.11$)$ & 0.415 & 70.6 & \multirow{2}{*}{0.204} \\
\hline & $<12.0$ years & 1 & $1.00(-3.67$ to 5.67$)$ & 0.674 & - & \\
\hline \multirow{2}{*}{ Insulinemia } & $\geq 12.0$ years & 4 & $-1.52(-5.36$ to 2.32$)$ & 0.437 & 50.6 & \multirow{2}{*}{0.805} \\
\hline & $<12.0$ years & 2 & $-2.13(-6.08$ to 1.83$)$ & 0.292 & 0.0 & \\
\hline \multirow{2}{*}{ TC } & $\geq 12.0$ years & 4 & $-6.88(-13.83$ to 0.06$)$ & 0.052 & 0.0 & \multirow{2}{*}{0.519} \\
\hline & $<12.0$ years & 1 & $1.00(-21.95$ to 23.95$)$ & 0.932 & - & \\
\hline \multirow{2}{*}{ HDL } & $\geq 12.0$ years & 3 & $1.24(-5.89$ to 8.38$)$ & 0.733 & 81.1 & \multirow{2}{*}{0.586} \\
\hline & $<12.0$ years & 1 & $0.00(-6.60$ to 6.60$)$ & 1.000 & - & \\
\hline \multirow{2}{*}{ LDL } & $\geq 12.0$ years & 3 & $-4.32(-13.82$ to 5.19$)$ & 0.373 & 51.2 & \\
\hline & $<12.0$ years & 1 & $4.00(-14.83$ to 22.83$)$ & 0.677 & - & 0.578 \\
\hline TG & $\geq 12.0$ years & 4 & $-5.70(-13.93$ to 2.52$)$ & 0.174 & 0.0 & \\
\hline $1 G$ & $<12.0$ years & 1 & $-9.00(-33.76$ to 15.76$)$ & 0.476 & - & 0.804 \\
\hline HOMA index & $\geq 12.0$ years & 4 & $-0.33(-0.67$ to 0.02$)$ & 0.062 & 0.0 & \\
\hline HUMA index & $<12.0$ years & 1 & $0.00(-1.43$ to 1.43$)$ & 1.000 & - & 0.663 \\
\hline $\mathrm{HbAlc}$ & $\geq 12.0$ years & 2 & $0.18(0.02$ to 0.34$)$ & 0.028 & 0.0 & 0067 \\
\hline HDAIC & $<12.0$ years & 1 & $0.00(-0.11$ to 0.11$)$ & 1.000 & - & $0.06 /$ \\
\hline Leptinemia & $\geq 12.0$ years & 2 & $-3.51(-14.57$ to 7.55$)$ & 0.534 & 88.8 & 0116 \\
\hline Leptinemia & $<12.0$ years & 1 & $7.00(-4.10$ to 18.10$)$ & 0.216 & - & 0.116 \\
\hline
\end{tabular}

bias for HDL ( $P$ value for Egger: $0.162 ; P$ value for Begg: 0.089; Supplemental 2).

3.16. Low Density Lipoprotein. The data regarding the effect of HIIT versus MICT on LDL were available in 4 trials. There was no significant difference between HIIT and MICT for LDL (WMD: -2.58 ; 95\% CI: -9.87 to $4.70 ; \quad P=0.487$; Figure 15), and moderate heterogeneity was detected across the included trials $\left(I^{2}=32.0 \% ; P=0.221\right)$. The results of sensitivity analysis (Supplemental 1 and Supplemental 3) and subgroup analysis were consistent with those of the overall analysis (Table 2). No significant publication bias was detected for LDL ( $P$ value for Egger: 0.552; $P$ value for Begg: 0.734; Supplemental 2).

3.17. Triglyceride. The data regarding the effect of HIIT versus MICT on TG were available from 5 trials. The results showed no significant differences between HIIT and MICT for TG was detected (WMD: -6.03 ; $95 \%$ CI: -13.83 to 1.77 ; $P=0.130$; Figure 16), and no evidence of heterogeneity among the included trials $\left(I^{2}=0.0 \% ; P=0.900\right)$. The results of sensitivity analysis (Supplemental 1 and Supplemental 3) and subgroup analysis were consistent with that of the overall analysis (Table 2). There was no significant publication bias 


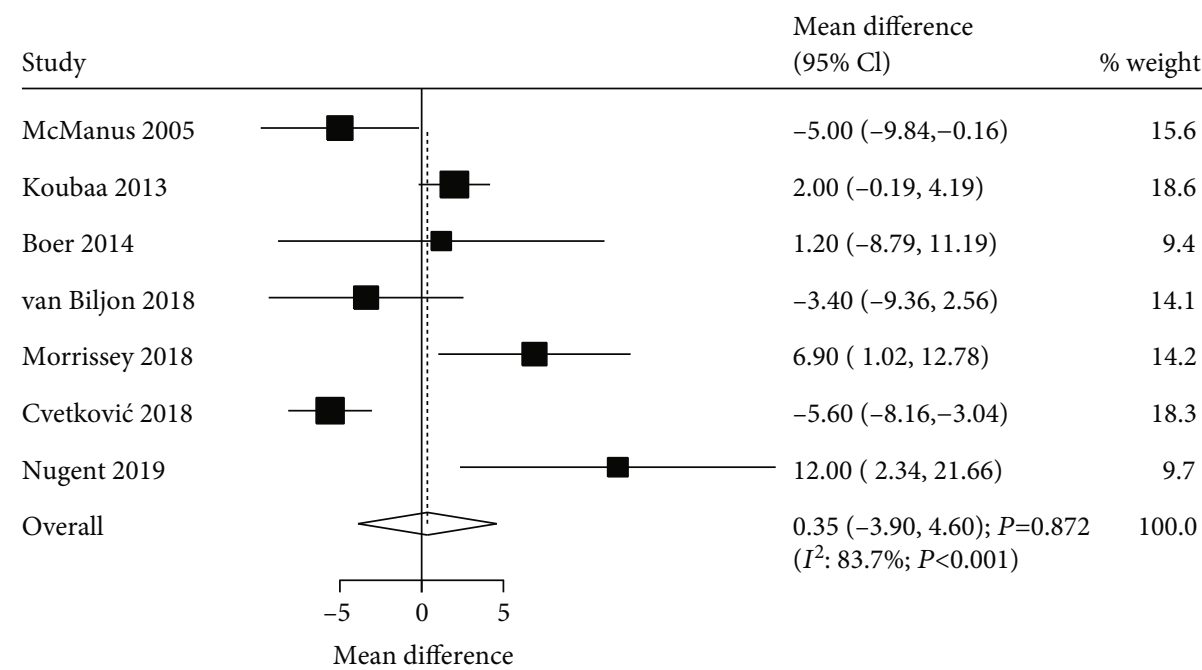

FIGURE 3: Effect of high-intensity interval training versus moderate-intensity continuous training on peak heart rate.

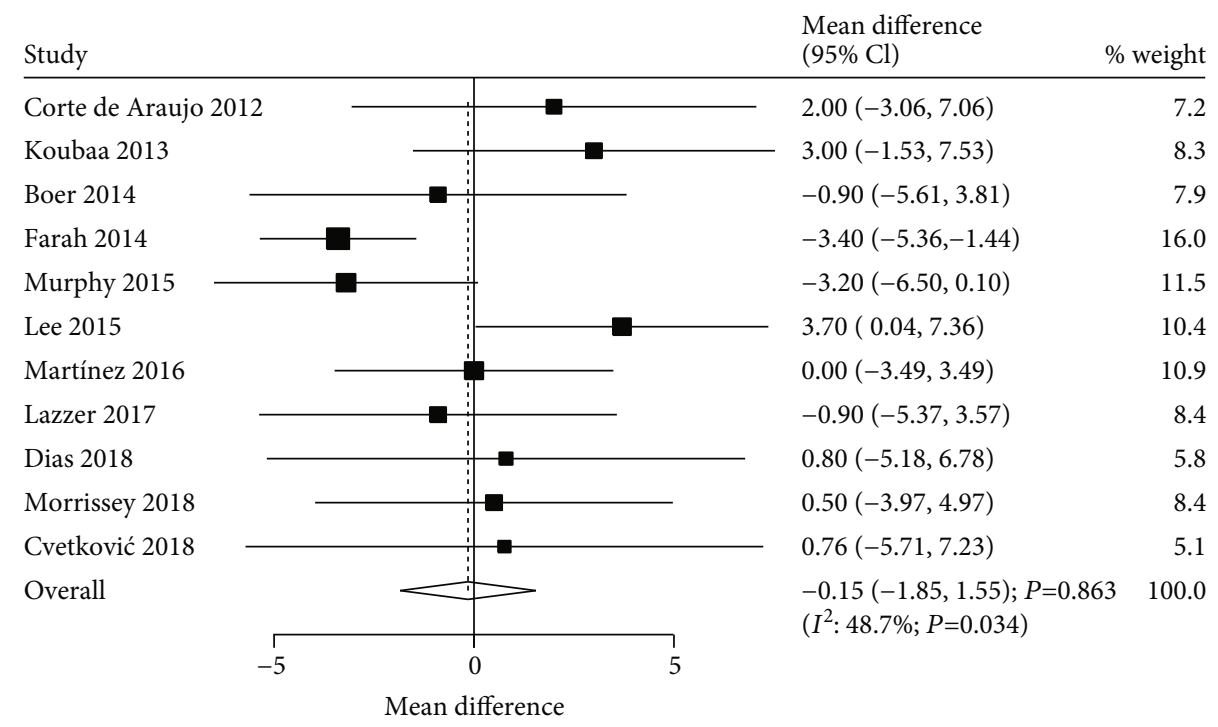

FIGURE 4: Effect of high-intensity interval training versus moderate-intensity continuous training on fat mass.

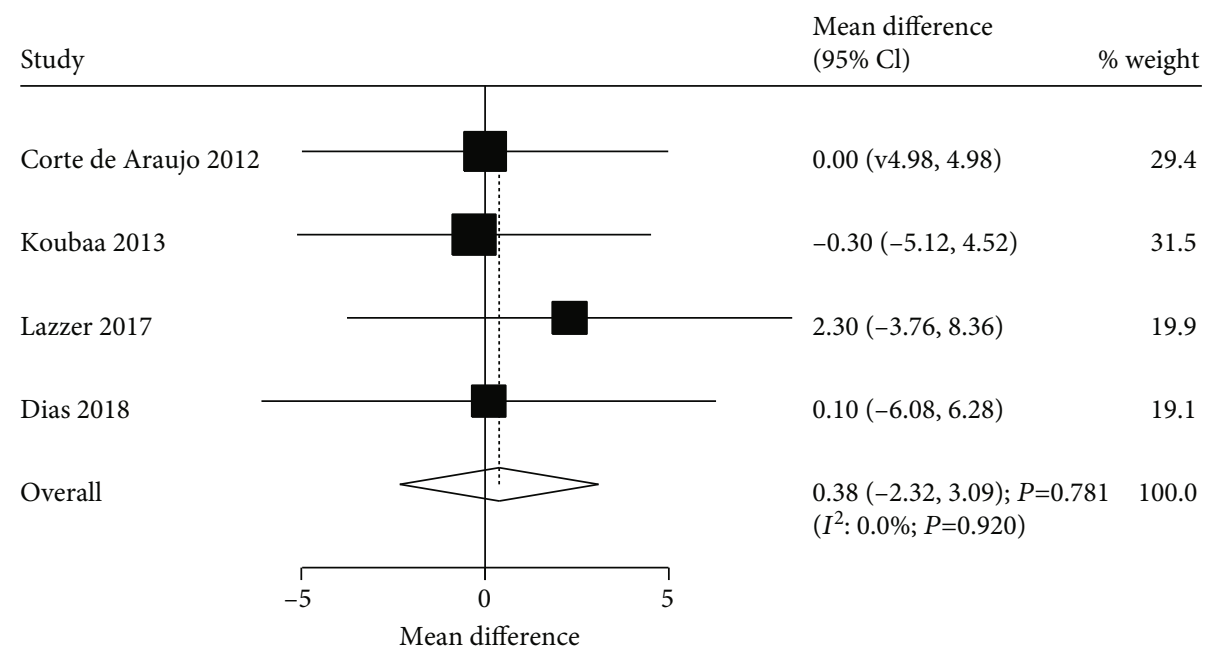

FIGURE 5: Effect of high-intensity interval training versus moderate-intensity continuous training on free fat mass. 


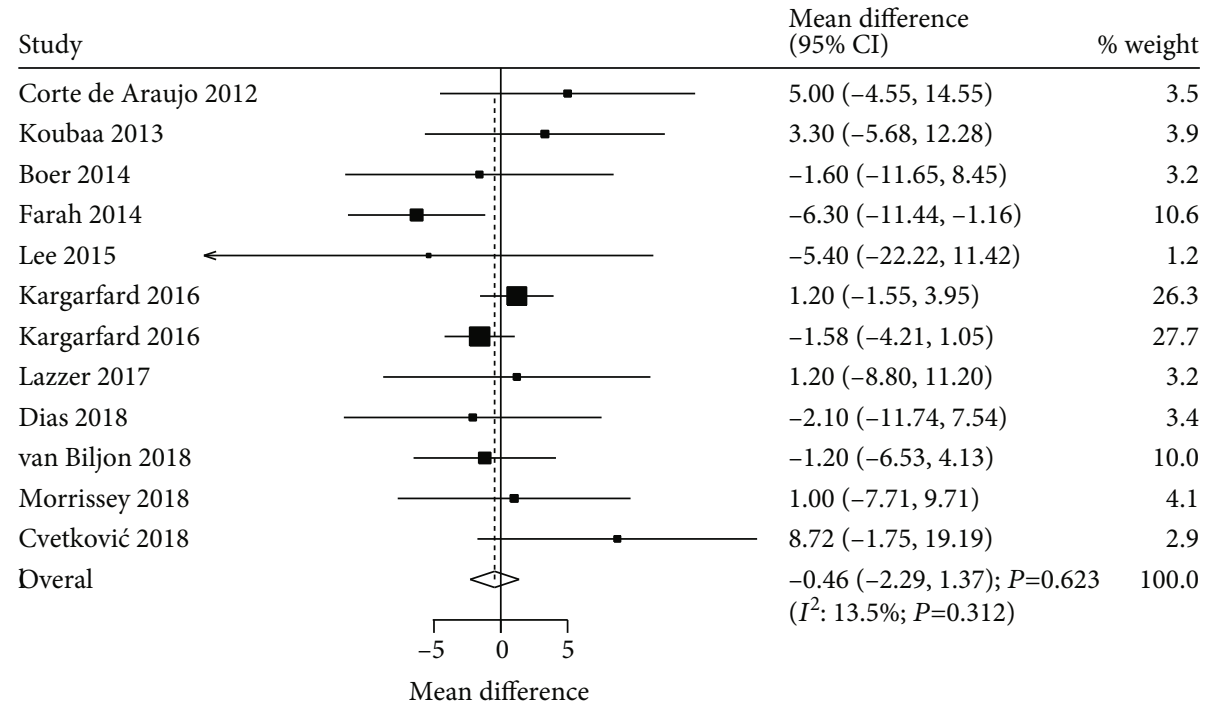

FIGURE 6: Effect of high-intensity interval training versus moderate-intensity continuous training on weight.

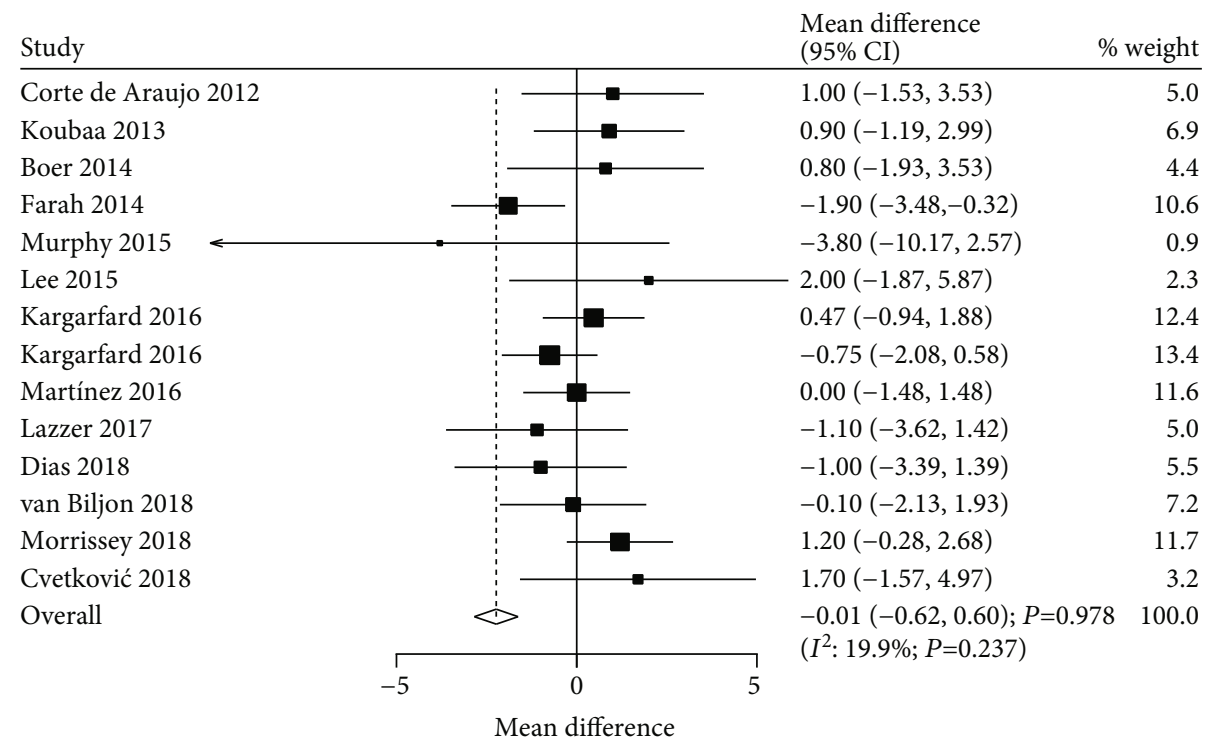

FIGURE 7: Effect of high-intensity interval training versus moderate-intensity continuous training on body mass index.

for TG ( $P$ value for Egger: 0.127; $P$ value for Begg: 0.221; Supplemental 2).

3.18. HOMA-IR. The data regarding the effect of HIIT versus MICT on HOMA-IR were available in 5 trials. The results showed no significant effect of HIIT on HOMA-IR as compared with MICT (WMD: $-0.31 ; 95 \% \mathrm{CI}:-0.64$ to $0.02 ; P=$ 0.070 ; Figure 17), and no evidence of heterogeneity was seen $\left(I^{2}=0.0 \% ; P=0.771\right)$. The results of sensitivity analysis (Supplemental 1 and Supplemental 3) and subgroup analysis were consistent with that of the overall analysis (Table 2). No significant publication bias for HOMA-IR was seen $(P$ value for Egger: 0.682; $P$ value for Begg: 1.000; Supplemental 2).

3.19. HbA1c. The data regarding the effect of HIIT versus MICT on HbAlc were available in 3 trials. The results showed no significant differences between HIIT and MICT (WMD: $0.08 ; 95 \% \mathrm{CI}:-0.06$ to $0.22 ; P=0.279$; Figure 18 ). Moreover, moderate heterogeneity for HbAlc was detected across the included trials $\left(I^{2}=40.5 \% ; P=0.186\right)$. Sensitivity analysis indicated that HIIT might increase HbAlc when compared with MICT (Supplemental 1 and Supplemental 3). Subgroup analysis suggested that HIIT significantly increased HbAlc when the mean age of children was $\geq 12.0$ years (WMD: 0.18; 95\% CI: 0.02 to $0.34 ; P=0.028$; Table 2). There was no significant publication bias detected for HbA1c ( $P$ value for Egger: 0.625; $P$ value for Begg: 1.000; Supplemental 2).

3.20. Leptinemia. The data regarding the effect of HIIT versus MICT on leptinemia were available in 3 trials. There was no significant difference between HIIT and MICT for leptinemia 


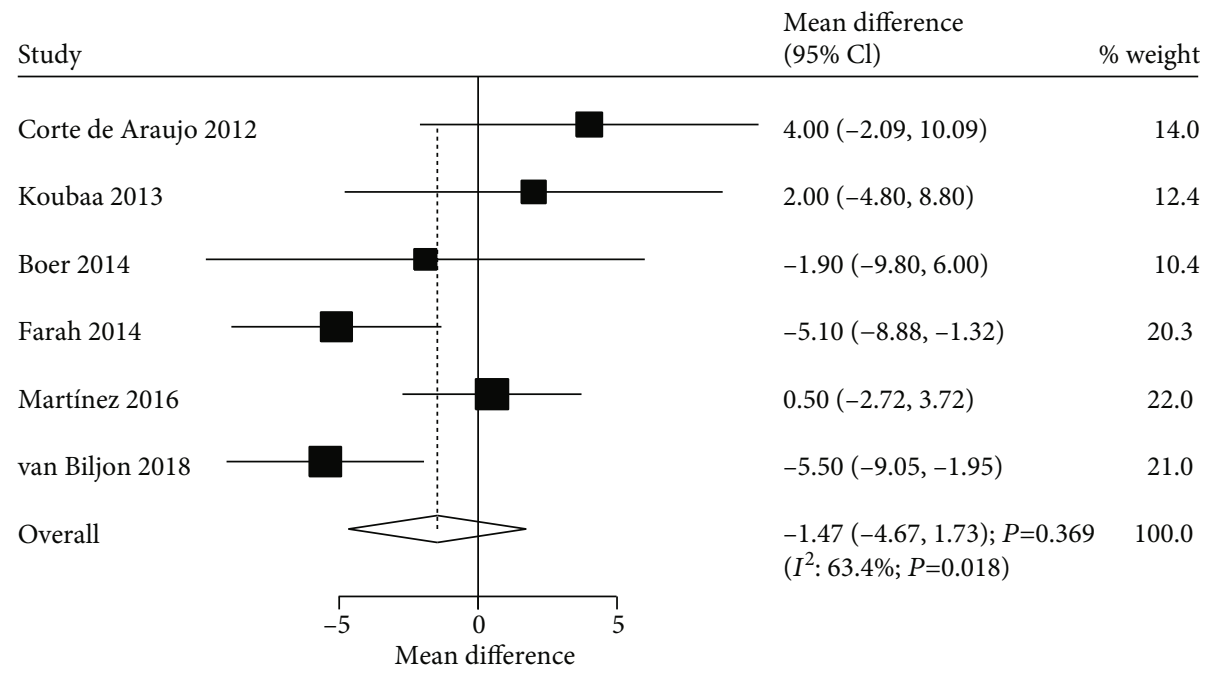

FIGURE 8: Effect of high-intensity interval training versus moderate-intensity continuous training on waist circumference.

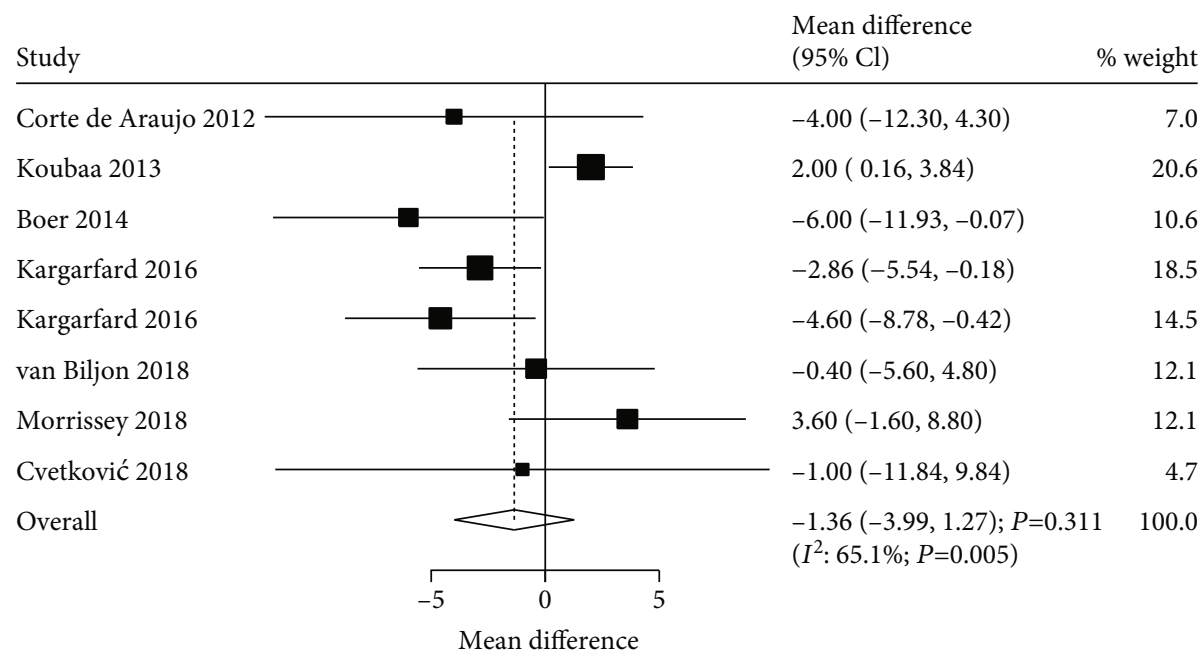

FIGURE 9: Effect of high-intensity interval training versus moderate-intensity continuous training on systolic blood pressure.

(WMD: $-0.77 ; 95 \% \mathrm{CI}:-9.89$ to $8.34 ; P=0.868$; Figure 19 ), and significant heterogeneity was detected among the included trials $\left(I^{2}=82.5 \% ; P=0.003\right)$. The results of sensitivity analysis (Supplemental 1 and Supplemental 3) and subgroup analysis were consistent with that of the overall analysis (Table 2). No significant publication bias was detected for leptinemia ( $P$ value for Egger: $0.888 ; P$ value for Begg: 1.000; Supplemental 2).

\section{Discussion}

This systematic review and meta-analysis was included RCTs that compared the effectiveness of HIIT and MICT on the health outcomes of children and adolescents. The findings of this meta-analysis found that HIIT could significantly improve peak $\mathrm{VO}_{2}$ when compared with MICT, and HIIT showed association with lower HDL and high HbA1c levels. Our results found that children in the HIIT group had high peak $\mathrm{VO}_{2}$ and $\mathrm{HbA} 1 \mathrm{c}$ than those in the MICT group when the mean age of children was $\geq 12.0$ years, and the $H_{R_{\max }}$ in children in the HIIT group was significantly lower than those in the MICT group if the mean age of children was $<12.0$ years. However, no significant differences were observed between HIIT and MICT on $\mathrm{HR}_{\max }$, fat mass, free fat mass, weight, BMI, WC, SBP, DBP, glycemia, insulinemia, TC, HDL, LDL, TG, HOMA-IR, HbAlc, and leptinemia.

Several systematic reviews and meta-analyses have investigated the effectiveness of HIIT. The meta-analysis conducted by Bacon et al. including 334 subjects aged $<45.0$ years from 37 studies revealed the association of HIIT with high peak $\mathrm{VO}_{2}$ [44]. A meta-analysis conducted by Costigan et al. suggested that HIIT was regarded as a feasible and timeefficient approach to improve CRF and body composition in adolescents [45]. Milanović et al. conducted in his metaanalysis included 723 healthy adults aged 18-45 years and revealed that both HIIT and endurance training showed significant improvement in peak $\mathrm{VO}_{2}$, and HIIT provided a greater improvement in peak $\mathrm{VO}_{2}$ than those who 


\begin{tabular}{|c|c|c|c|}
\hline \multicolumn{2}{|l|}{ Study } & \multirow{2}{*}{$\begin{array}{l}\text { Mean difference } \\
(95 \% \mathrm{Cl})\end{array}$} & \multirow{2}{*}{$\begin{array}{r}\text { \% weight } \\
6.8\end{array}$} \\
\hline Corte de Araujo 2012 & 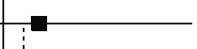 & & \\
\hline Koubaa 2013 & & $1.00(-1.19,3.19)$ & 26.4 \\
\hline Boer 2014 & & $4.00(-1.93,9.93)$ & 3.6 \\
\hline Kargarfard 2016 & & $-0.39(-3.02,2.24)$ & 18.2 \\
\hline Kargarfard 2016 & & $-0.26(-3.06,2.54)$ & 16.1 \\
\hline van Biljon 2018 & & $-1.00(-3.99,1.99)$ & 14.1 \\
\hline Morrissey 2018 & & $2.50(-0.99,5.99)$ & 10.3 \\
\hline Cvetković 2018 & & $2.00(-3.32,7.32)$ & 4.5 \\
\hline Overall & & $\begin{array}{l}0.57(-0.55,1.69) ; P=0.321 \\
\left(I^{2}: 0.0 \% ; P=0.681\right)\end{array}$ & 100.0 \\
\hline-5 & 5 & & \\
\hline
\end{tabular}

FIGURE 10: Effect of high-intensity interval training versus moderate-intensity continuous training on diastolic blood pressure.

\begin{tabular}{|c|c|c|}
\hline Study & $\begin{array}{l}\text { Mean difference } \\
(95 \% \mathrm{Cl})\end{array}$ & $\%$ weight \\
\hline Corte de Araujo 2012 & $1.00(-3.67,5.67)$ & 33.8 \\
\hline Boer 2014 & $0.00(-4.25,4.25)$ & 35.3 \\
\hline Lee 2015 & $7.00(-20.52,34.52)$ & 3.6 \\
\hline Morrissey 2018 & $-10.00(-16.55,-3.45)$ & 27.3 \\
\hline Overall & $\begin{array}{l}-2.14(-7.62,3.35) ; P=0.445 \\
\left(I^{2}: 64.3 \% ; P=0.038\right)\end{array}$ & 100.0 \\
\hline
\end{tabular}

FIGURE 11: Effect of high-intensity interval training versus moderate-intensity continuous training on glycemia.

underwent endurance training [46]. A meta-analysis conducted by García-Hermoso et al. included 9 studies and suggested that HIIT is considered as an effective and timeefficient approach to improve blood pressure and aerobic capacity levels than other forms of training in overweight and obese adolescents [47]. Maillard et al. conducted a meta-analysis by including 39 studies and found that HIIT could reduce fat-mass deposits in normal weight and overweight/obese adults [12]. Thivel et al. reported that HIIT significantly improved the maximal oxygen uptake and reduced body mass, body fat, SBP, DBP, and HOMA-IR in overweight and obese children and adolescents [48]. A metaanalysis conducted by Depiazzi et al. found that aquatic HIIT significantly improved the aerobic performance and lower limb strength in a nonathletic population [49]. A metaanalysis conducted by Cao et al. found that HIIT versus MICT showed significant improvement in CRF in children and adolescents [16]. However, the comprehensive health outcomes between HIIT and MICT in children and adolescents were not reported in prior studies. Therefore, the current meta-analysis was conducted to compare the effectiveness of HIIT with MICT in children and adolescents.

The current study revealed that HIIT significantly improved the peak $\mathrm{VO}_{2}$ than MICT, and the significant difference between the groups was mainly observed if the mean age of children was $\geq 12.0$ years. Although the pooled results were consistent with those in the previous meta-analysis study, irrespective for adults or children $[16,46]$, they applied standard mean difference as an effect estimate, and no stratification was done by the mean age of the subjects. The potential mechanism for this could be that HIIT versus MICT displayed a greater increase in mitochondrial content, including citrate synthase maximal activity, type II fiber activation, adenosine monophosphate activated protein kinase activity, and mass-specific oxygen flux [50, 51]. Also, HIIT played an important role on central adaptation, including 


\begin{tabular}{|c|c|c|}
\hline Study & $\begin{array}{l}\text { Mean difference } \\
\quad(95 \% \mathrm{CI})\end{array}$ & \% Weight \\
\hline Corte de Araujo 2012 & $-1.00(-6.06,4.06)$ & 17.2 \\
\hline Boer 2014 & $-1.00(-4.05,2.05)$ & 33.1 \\
\hline Farah 2014 & $3.20(-4.28,10.68)$ & 9.1 \\
\hline Lee 2015 & $-27.80(-54.03,-1.57)$ & 0.8 \\
\hline van Biljon 2018 & $-3.90(-10.25,2.45)$ & 12.0 \\
\hline Morrissey 2018 & $-2.90(-6.45,0.65)$ & 27.9 \\
\hline Overall & $\begin{array}{l}-1.72(-4.13,0.69) ; P=0.163 \\
(I \text {-square: } 24.5 \% ; P=0.250)\end{array}$ & 100.0 \\
\hline
\end{tabular}

FIGURE 12: Effect of high-intensity interval training versus moderate-intensity continuous training on insulinemia.

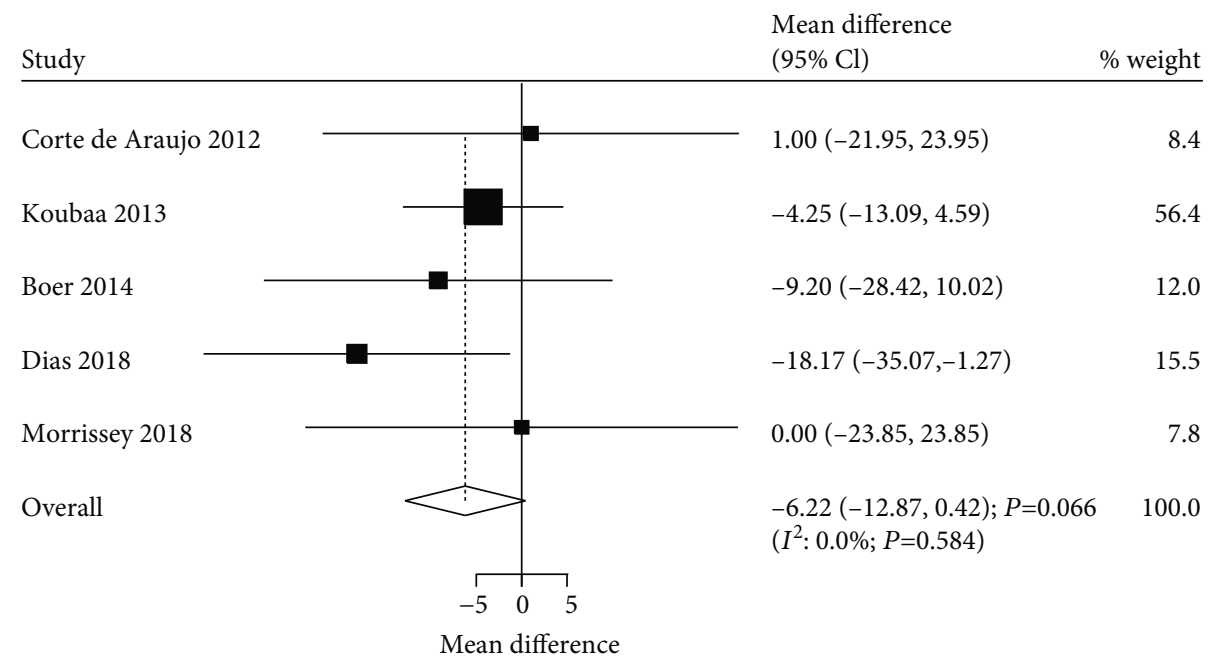

FIGURE 13: Effect of high-intensity interval training versus moderate-intensity continuous training on total cholesterol.

\begin{tabular}{|c|c|c|c|}
\hline Study & & $\begin{array}{l}\text { Mean difference } \\
(95 \% \mathrm{Cl})\end{array}$ & $\%$ weight \\
\hline Corte de Araujo 2012 & 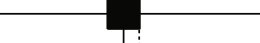 & $0.00(-6.60,6.60)$ & 22.8 \\
\hline Koubaa 2013 & & $-3.48(-6.02,-0.94)$ & 33.2 \\
\hline Boer 2014 & & $9.70(2.07,17.33)$ & 20.3 \\
\hline Dias 2018 & & $-0.39(-6.69,5.91)$ & 23.6 \\
\hline Overall & & $\begin{array}{l}0.73(-4.49,5.94) ; P=0.785 \\
\left(I^{2}: 72.5 \% ; P=0.012\right)\end{array}$ & 100.0 \\
\hline & $\begin{array}{ll} & 1 \\
0 & 5\end{array}$ & & \\
\hline
\end{tabular}

FIGURE 14: Effect of high-intensity interval training versus moderate-intensity continuous training on high density lipoprotein. 


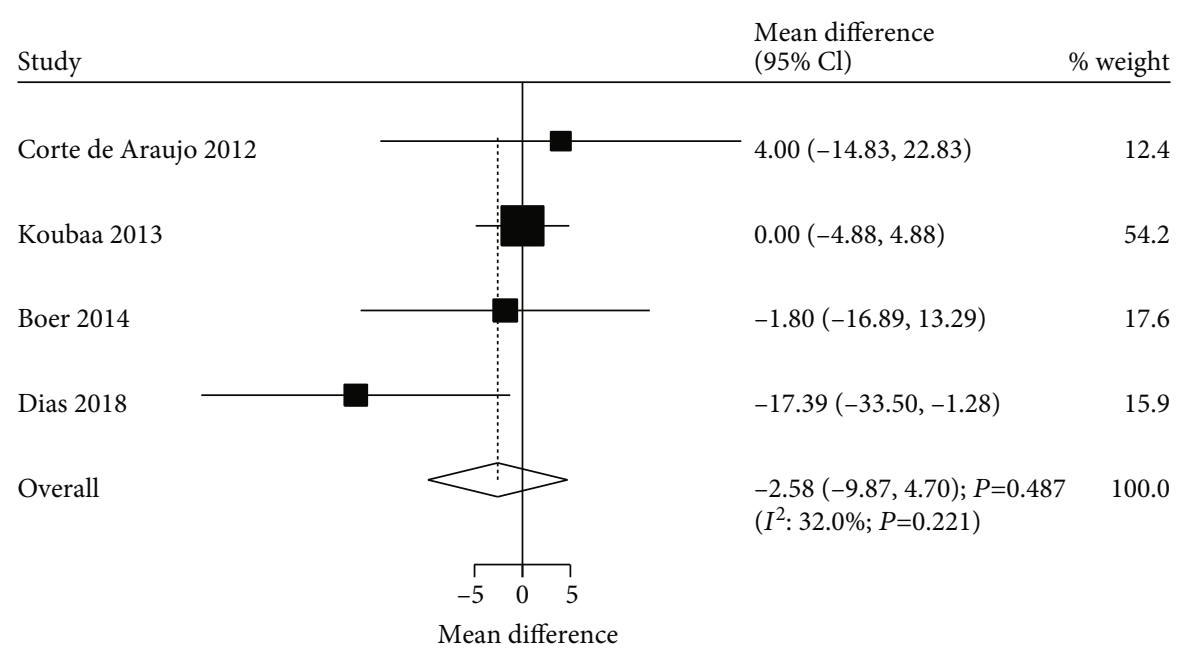

FIGURE 15: Effect of high-intensity interval training versus moderate-intensity continuous training on low density lipoprotein.

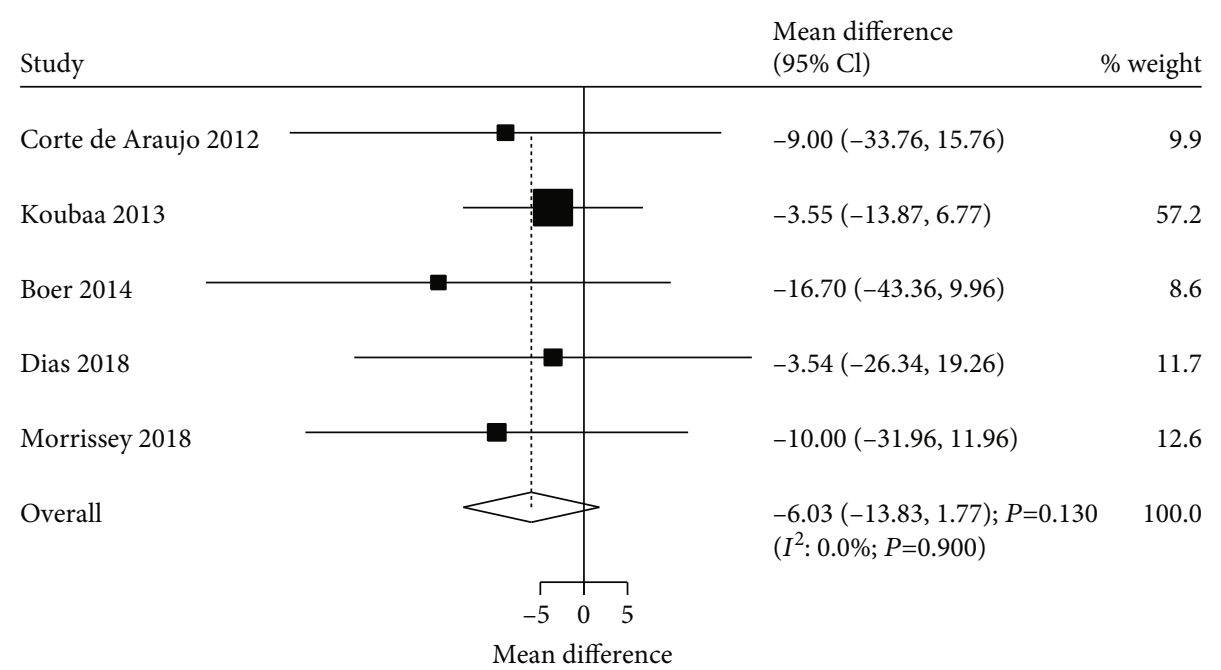

FIGURE 16: Effect of high-intensity interval training versus moderate-intensity continuous training on triglycerides.

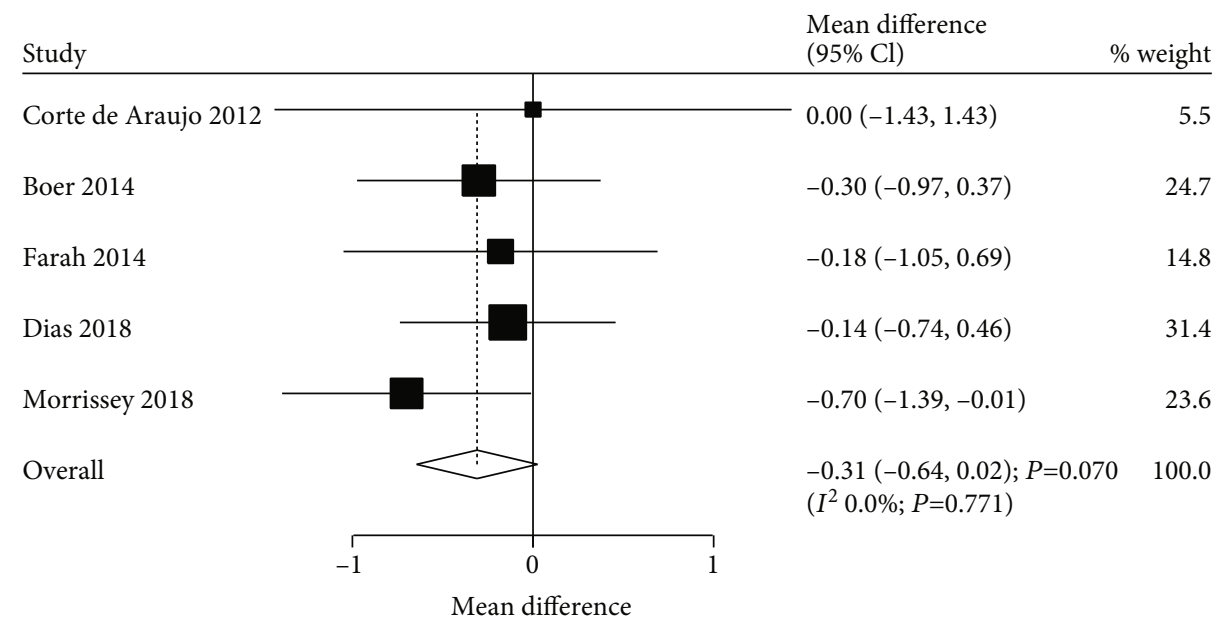

FIGURE 17: Effect of high-intensity interval training versus moderate-intensity continuous training on HOMA-IR. 


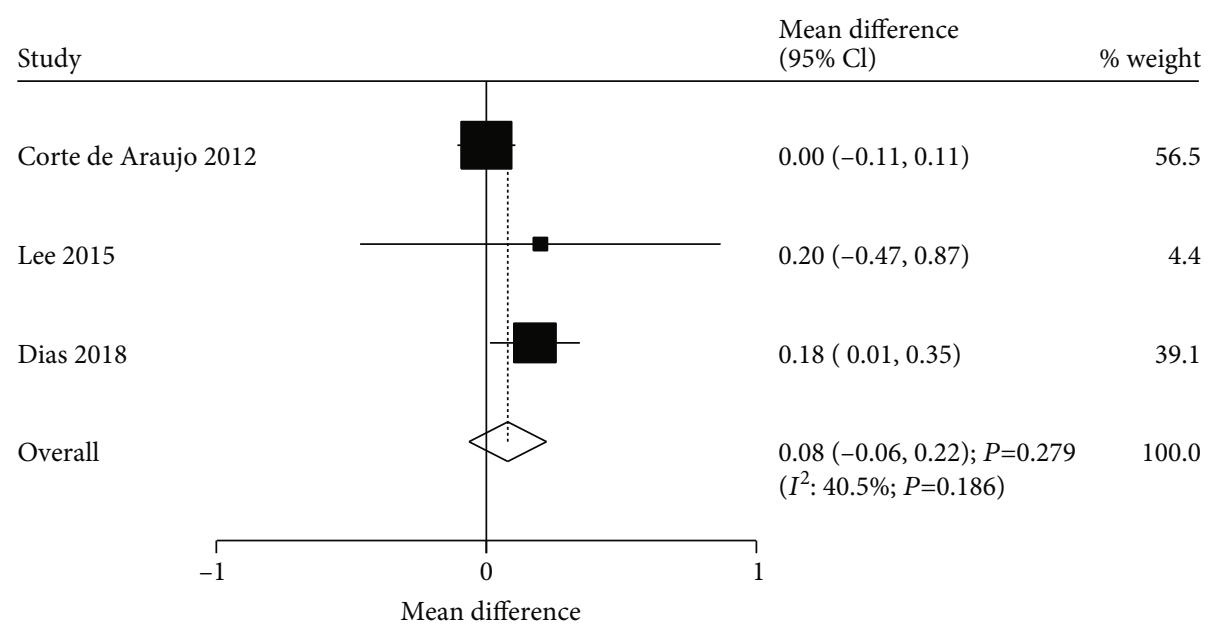

FIGURE 18: Effect of high-intensity interval training versus moderate-intensity continuous training on HbAlc.

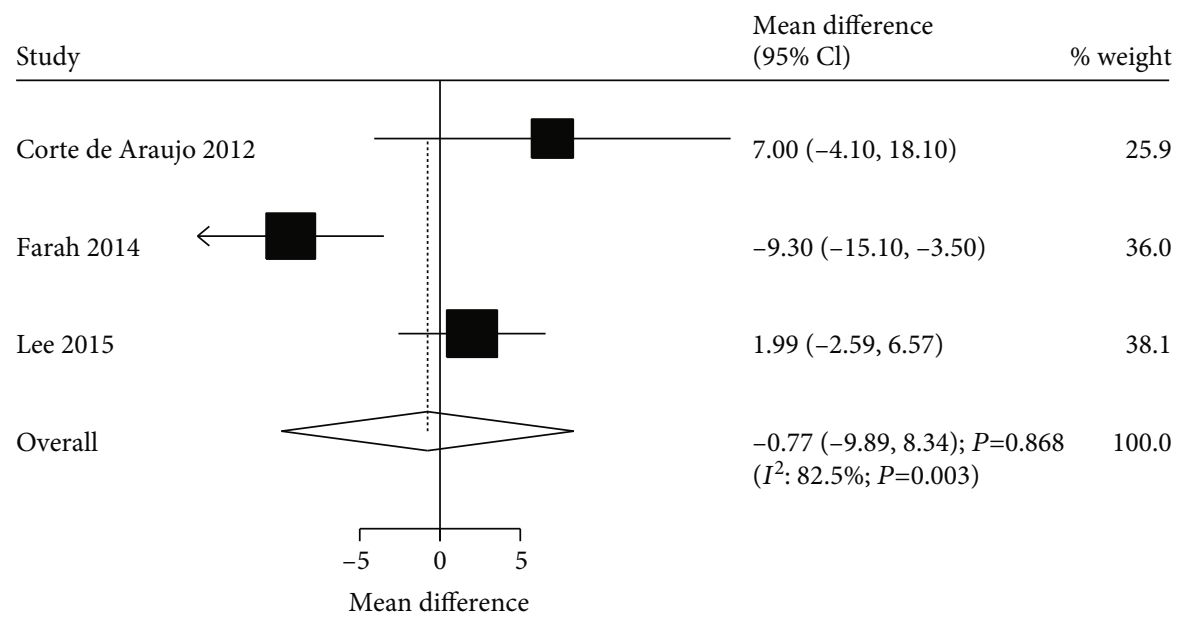

FIGURE 19: Effect of high-intensity interval training versus moderate-intensity continuous training on leptinemia.

maximal stroke volume, cardiac output, and blood volume [52-54]. Finally, the improvement of peak $\mathrm{VO}_{2}$ in the HIIT group was more evident in children aged 12.0 years or more, which could be explained by the intensity and regularity of training.

In this study, no significant differences between HIIT and MICT for $\mathrm{HR}_{\max }$, fat mass, free fat mass, weight, BMI, WC, SBP, DBP, glycemia, insulinemia, TC, HDL, LDL, TG, HOMA-IR, HbAlc, and leptinemia were observed, which was not consistent with that of the previous findings. However, the results of HDL and HbAlc between the groups were not robust. The potential reason for this could be that smaller number of included trials reported these parameters, and the power was not enough to obtain a stable result between the HIIT and the MICT groups. Moreover, HbAlc was increased in the HIIT group if the mean age of children was $\geq 12.0$ years. This result showed correlation with high energy intake after training in older children. Interestingly, HIIT showed association with low $\mathrm{HR}_{\max }$ than MICT if the children were $<12.0$ years age. However, this result was based on 2 included tri- als, and so large-scale RCT should be conducted to verify the result.

There are several strengths in this study that should be highlighted: (1) this study provided the comprehensive health results between HIIT and MICT in children and adolescents; (2) the analysis of this study was based on RCTs, which included high evidence level results; (3) the analysis was based on inclusion of large number of trials, and the results were robust than any individual trial, and (4) stratified analyses for investigated outcomes according to the mean age of subjects were also conducted. Although above strengths, the limitations of this study should be acknowledged: (1) a smaller number of children were included in individual study, and the deviation was large that could affect the robustness of pooled conclusions; (2) various training types and intensities were included, which could affect the net effects between HIIT and MICT; (3) the status of subjects varied, and the place of training showed significant correlation with health outcomes; (4) several outcomes stratified by the mean age were restricted owing to only 1 study included; (5) whether the effectiveness between HIIT and 
MICT are differing based on weight status and sexual maturation were not conducted owing to mostly studies did not reported data stratified by weight status and sexual maturation; (6) the data abstracted was based on pooled results in each trial, restricting us in conducting a more detailed analysis; and (7) this analysis was based on published RCTs, and so publication bias was considered inevitable.

\section{Conclusions}

In summary, a high peak $\mathrm{VO}_{2}$ in the HIIT group was observed than in the MICT group in children and adolescents. Sensitivity analyses suggested that the levels of HDL and HbA1c might differ between the HIIT and the MICT groups. Finally, the effects of HIIT versus MICT on peak $\mathrm{VO}_{2}, \mathrm{HR}_{\text {max }}$, and $\mathrm{HbAlc}$ might differ based on the mean age of the subjects. The long-term effects of HIIT versus MICT in children and adolescents require assessment in further large-scale RCTs.

\section{Conflicts of Interest}

The authors declare that there is no conflict of interest regarding the publication of this paper.

\section{Authors' Contributions}

Jun Yin and Zhixiong Zhou contributed equally to this work.

\section{Acknowledgments}

This work was supported by the support program for Highlevel Teacher Team Development of Beijing Municipal Institutions (IDHT20170515) and Serving National Special Needs in Doctoral Talents Development Program-Performance Training and Health Promotion for Adolescents.

\section{Supplementary Materials}

Supplemental 1 Figure S1: sensitivity analysis of high-intensity interval training versus moderate-intensity continuous training on peak $\mathrm{VO}_{2}$. Figure S2: sensitivity analysis of highintensity interval training versus moderate-intensity continuous training on peak heart rate. Figure S3: sensitivity analysis of high-intensity interval training versus moderate-intensity continuous training on fat mass. Figure S4: sensitivity analysis of high-intensity interval training versus moderate-intensity continuous training on free fat mass. Figure S5: sensitivity analysis of high-intensity interval training versus moderateintensity continuous training on weight. Figure S6: sensitivity analysis of high-intensity interval training versus moderateintensity continuous training on body mass index. Figure S7: sensitivity analysis of high-intensity interval training versus moderate-intensity continuous training on waist circumference. Figure S8: sensitivity analysis of high-intensity interval training versus moderate-intensity continuous training on systolic blood pressure. Figure S9: sensitivity analysis of high-intensity interval training versus moderate-intensity continuous training on diastolic blood pressure. Figure S10: sensitivity analysis of high-intensity interval training versus moderate-intensity continuous training on glycemia. Figure S11: sensitivity analysis of high-intensity interval training versus moderate-intensity continuous training on insulinemia. Figure S12: sensitivity analysis of high-intensity interval training versus moderate-intensity continuous training on total cholesterol. Figure S13: sensitivity analysis of high-intensity interval training versus moderate-intensity continuous training on high density lipoprotein. Figure S14: sensitivity analysis of high-intensity interval training versus moderate-intensity continuous training on low density lipoprotein. Figure S15: sensitivity analysis of high-intensity interval training versus moderate-intensity continuous training on triglycerides. Figure S16: sensitivity analysis of high-intensity interval training versus moderate-intensity continuous training on HOMAIR. Figure S17: sensitivity analysis of high-intensity interval training versus moderate-intensity continuous training on HbA1c. Figure S18: sensitivity analysis of high-intensity interval training versus moderate-intensity continuous training on leptinemia. Supplemental 2 Figure S1: funnel plot of highintensity interval training versus moderate-intensity continuous training on peak oxygen uptake $\left(\mathrm{VO}_{2}\right)$. Figure $\mathrm{S} 2$ : funnel plot of high-intensity interval training versus moderateintensity continuous training on peak heart rate. Figure S3: funnel plot of high-intensity interval training versus moderate-intensity continuous training on fat mass. Figure S4: results of Trim and fill method for high-intensity interval training versus moderate-intensity continuous training on fat mass. Figure S5: funnel plot of high-intensity interval training versus moderate-intensity continuous training on free fat mass. Figure S6: funnel plot of high-intensity interval training versus moderate-intensity continuous training on weight. Figure S7: funnel plot of high-intensity interval training versus moderate-intensity continuous training on body mass index. Figure S8: Funnel plot of high-intensity interval training versus moderate-intensity continuous training on waist circumference. Figure S9: funnel plot of high-intensity interval training versus moderate-intensity continuous training on systolic blood pressure. Figure S10: funnel plot of highintensity interval training versus moderate-intensity continuous training on diastolic blood pressure. Figure S11: funnel plot of high-intensity interval training versus moderateintensity continuous training on glycemia. Figure S12: funnel plot of high-intensity interval training versus moderateintensity continuous training on insulinemia. Figure S13: funnel plot of high-intensity interval training versus moderateintensity continuous training on total cholesterol. Figure S14: funnel plot of high-intensity interval training versus moderate-intensity continuous training on high density lipoprotein. Figure S15: funnel plot of high-intensity interval training versus moderate-intensity continuous training on low density lipoprotein. Figure S16: funnel plot of highintensity interval training versus moderate-intensity continuous training on triglycerides. Figure S17: funnel plot of highintensity interval training versus moderate-intensity continuous training on HOMA-IR. Figure S18: funnel plot of highintensity interval training versus moderate-intensity continuous training on HbA1c. Figure S19: funnel plot of highintensity interval training versus moderate-intensity continuous training on leptinemia. Supplemental 3 Table S1: 
sensitivity analysis of high-intensity interval training versus moderate-intensity continuous training on peak $\mathrm{VO}_{2}$. Table S2: sensitivity analysis of high-intensity interval training versus moderate-intensity continuous training on peak heart rate. Table S3: sensitivity analysis of high-intensity interval training versus moderate-intensity continuous training on fat mass. Table S4: sensitivity analysis of high-intensity interval training versus moderate-intensity continuous training on free fat mass. Table S5: sensitivity analysis of high-intensity interval training versus moderate-intensity continuous training on weight. Table S6: sensitivity analysis of high-intensity interval training versus moderate-intensity continuous training on body mass index. Table S7: sensitivity analysis of highintensity interval training versus moderate-intensity continuous training on waist circumference. Table S8: sensitivity analysis of high-intensity interval training versus moderateintensity continuous training on systolic blood pressure. Table S9: sensitivity analysis of high-intensity interval training versus moderate-intensity continuous training on diastolic blood pressure. Table S10: sensitivity analysis of high-intensity interval training versus moderate-intensity continuous training on glycemia. Table S11: sensitivity analysis of high-intensity interval training versus moderate-intensity continuous training on insulinemia. Table S12: sensitivity analysis of highintensity interval training versus moderate-intensity continuous training on total cholesterol. Table S13: sensitivity analysis of high-intensity interval training versus moderate-intensity continuous training on high density lipoprotein. Table S14: sensitivity analysis of high-intensity interval training versus moderate-intensity continuous training on low density lipoprotein. Table S15: sensitivity analysis of high-intensity interval training versus moderate-intensity continuous training on triglycerides. Table S16: sensitivity analysis of high-intensity interval training versus moderate-intensity continuous training on HOMA-IR. Table S17: sensitivity analysis of highintensity interval training versus moderate-intensity continuous training on HbAlc. Table S18: Sensitivity analysis of high-intensity interval training versus moderate-intensity continuous training on leptinemia (Supplementary Materials)

\section{References}

[1] X. Sui, M. J. LaMonte, and S. N. Blair, "Cardiorespiratory fitness as a predictor of nonfatal cardiovascular events in asymptomatic women and men," American Journal of Epidemiology, vol. 165, no. 12, pp. 1413-1423, 2007.

[2] D. L. Swift, C. J. Lavie, N. M. Johannsen et al., "Physical activity, cardiorespiratory fitness, and exercise training in primary and secondary coronary prevention," Circulation Journal, vol. 77, no. 2, pp. 281-292, 2013.

[3] R. Ross, S. N. Blair, R. Arena et al., "Importance of assessing cardiorespiratory fitness in clinical practice: a case for fitness as a clinical vital sign: a scientific statement from the American Heart Association," Circulation, vol. 134, no. 24, pp. e653e699, 2016.

[4] S. Kodama, K. Saito, S. Tanaka et al., "Cardiorespiratory fitness as a quantitative predictor of all-cause mortality and cardiovascular events in healthy men and women: a meta-analysis," JAMA, vol. 301, no. 19, pp. 2024-2035, 2009.
[5] G. R. Tomkinson and T. S. Olds, "Secular changes in pediatric aerobic fitness test performance: the global picture," Medicine and Sport Science, vol. 50, pp. 46-66, 2007.

[6] J. R. Ruiz, J. Castro-Pinero, E. G. Artero et al., "Predictive validity of health-related fitness in youth: a systematic review," British Journal of Sports Medicine, vol. 43, no. 12, pp. 909-923, 2009.

[7] C. J. Lavie, R. Arena, D. L. Swift et al., "Exercise and the cardiovascular system: clinical science and cardiovascular outcomes," Circulation Research, vol. 117, no. 2, pp. 207-219, 2015.

[8] G. Baquet, F. X. Gamelin, P. Mucci, D. Thevenet, E. Van Praagh, and S. Berthoin, "Continuous vs. interval aerobic training in 8- to 11-year-old children," Journal of Strength and Conditioning Research, vol. 24, no. 5, pp. 1381-1388, 2010.

[9] S. A. Costigan, N. Eather, R. C. Plotnikoff et al., "Preliminary efficacy and feasibility of embedding high intensity interval training into the school day: a pilot randomized controlled trial," Preventive Medicine Reports, vol. 2, pp. 973-979, 2015.

[10] S. A. Costigan, N. Eather, R. C. Plotnikoff, C. H. Hillman, and D. R. Lubans, "High-intensity interval training for cognitive and mental health in adolescents," Medicine \& Science in Sports \& Exercise, vol. 48, no. 10, pp. 1985-1993, 2016.

[11] C. Lonsdale, R. R. Rosenkranz, L. R. Peralta, A. Bennie, P. Fahey, and D. R. Lubans, "A systematic review and metaanalysis of interventions designed to increase moderate-tovigorous physical activity in school physical education lessons," Preventive Medicine, vol. 56, no. 2, pp. 152-161, 2013.

[12] F. Maillard, B. Pereira, and N. Boisseau, "Effect of highintensity interval training on total, abdominal and visceral fat mass: a meta-analysis," Sports Medicine, vol. 48, no. 2, pp. 269-288, 2018.

[13] E. C. Costa, J. L. Hay, D. S. Kehler et al., "Effects of highintensity interval training versus moderate-intensity continuous training on blood pressure in adults with pre- to established hypertension: a systematic review and meta-analysis of randomized trials," Sports Medicine, vol. 48, no. 9, pp. 21272142, 2018.

[14] E. A. Jo, K. I. Cho, J. J. Park, D. S. Im, J. H. Choi, and B. J. Kim, "Effects of high-intensity interval training versus moderateintensity continuous training on epicardial fat thickness and endothelial function in hypertensive metabolic syndrome," Metabolic Syndrome and Related Disorders, vol. 18, no. 2, pp. 96-102, 2020.

[15] A. T. De Nardi, T. Tolves, T. L. Lenzi, L. U. Signori, and A. M. V. da Silva, "High-intensity interval training versus continuous training on physiological and metabolic variables in prediabetes and type 2 diabetes: a meta-analysis," Diabetes Research and Clinical Practice, vol. 137, pp. 149-159, 2018.

[16] M. Cao, M. Quan, and J. Zhuang, "Effect of High-Intensity Interval Training versus moderate-intensity continuous training on cardiorespiratory fitness in children and adolescents: a meta-analysis," International Journal of Environmental Research and Public Health, vol. 16, no. 9, p. 1533, 2019.

[17] J. X. Liu, L. Zhu, and J. M. Deng, "The effects of high-intensity interval training versus moderate-intensity continuous training on fat loss and cardiometabolic health in pediatric obesity: a protocol of systematic review and meta-analysis," Medicine, vol. 98, no. 10, article e14751, 2019.

[18] D. Moher, A. Liberati, J. Tetzlaff, D. G. Altman, and The PRISMA Group, "Preferred reporting items for systematic 
reviews and meta-analyses: the PRISMA statement," PLoS Medicine, vol. 6, no. 7, article e1000097, 2009.

[19] A. R. Jadad, R. A. Moore, D. Carroll et al., "Assessing the quality of reports of randomized clinical trials: is blinding necessary?," Controlled Clinical Trials, vol. 17, no. 1, pp. 1-12, 1996.

[20] R. Der Simonian and N. Laird, "Meta-analysis in clinical trials," Control Clinical Trials, vol. 7, no. 3, pp. 177-188, 1986.

[21] A. E. Ades, G. Lu, and J. P. Higgins, "The interpretation of random-effects meta-analysis in decision models," Medical Decision Making, vol. 25, no. 6, pp. 646-654, 2016.

[22] J. J. Deeks, J. P. T. Higgins, and D. G. Altman, "Analyzing Data and Undertaking Meta-Analyses," in Cochrane Handbook for Systematic Reviews of Interventions 501, The Cochrane Collaboration, U.K., 2008.

[23] J. P. Higgins, S. G. Thompson, J. J. Deeks, and D. G. Altman, "Measuring inconsistency in meta-analyses," BMJ, vol. 327, no. 7414, pp. 557-560, 2003.

[24] A. Tobias, "Assessing the influence of a single study in metaanalysis," Stata Tech Bull Reprints, vol. 47, p. 17, 1999.

[25] J. J. Deeks, D. G. Altman, and M. J. Bradburn, "Statistical methods for examining heterogeneity and combining results from several studies in meta-analysis," in Systematic Reviews in Health Care, BMJ Books, London, 2001.

[26] M. Egger, G. Davey Smith, M. Schneider, and C. Minder, "Bias in meta-analysis detected by a simple, graphical test," British Medical Journal, vol. 315, no. 7109, pp. 629-634, 1997.

[27] C. B. Begg and M. Mazumdar, "Operating characteristics of a rank correlation test for publication bias," Biometrics, vol. 50, no. 4, pp. 1088-1101, 1994.

[28] A. M. McManus, C. H. Cheng, M. P. Leung, T. C. Yung, and D. J. Macfarlane, "Improving aerobic power in primary school boys: a comparison of continuous and interval training," International Journal of Sports Medicine, vol. 26, no. 9, pp. 781-786, 2005.

[29] A. C. C. De Araujo, H. Roschel, A. R. Picanço et al., "Similar health benefits of endurance and high-intensity interval training in obese children," PLoS One, vol. 7, no. 8, article e42747, 2012.

[30] A. Koubaa, "Effect of intermittent and continuous training on body composition cardiorespiratory fitness and lipid profile in obese adolescents," IOSR Journal of Pharmacy, vol. 3, pp. 3137, 2013.

[31] P.-H. Boer, M. Meeus, E. Terblanche et al., "The influence of sprint interval training on body composition, physical and metabolic fitness in adolescents and young adults with intellectual disability: a randomized controlled trial," Clinical Rehabilitation, vol. 28, no. 3, pp. 221-231, 2014.

[32] B. Q. Farah, R. M. Ritti-Dias, P. B. Balagopal, J. O. Hill, and W. L. Prado, "Does exercise intensity affect blood pressure and heart rate in obese adolescents? A 6-month multidisciplinary randomized intervention study," Pediatric Obesity, vol. 9, no. 2, pp. 111-120, 2014.

[33] B. E. Starko, I. U. Eneli, and A. E. Bonny, "Estimated aerobic capacity changes in adolescents with obesity following high intensity interval exercise," International Journal of Kinesiology and Sports Science, vol. 2, pp. 1-8, 2014.

[34] A. Murphy, C. Kist, A. J. Gier, N. M. Edwards, Z. Gao, and R. M. Siegel, "The feasibility of high-intensity interval exercise in obese adolescents," Clinical Pediatrics, vol. 54, no. 1, pp. 8790, 2015.
[35] S. S. Lee, J. H. Yoo, and Y. S. So, "Effect of the low- versus highintensity exercise training on endoplasmic reticulum stress and GLP-1 in adolescents with type 2 diabetes mellitus," Journal of Physical Therapy Science, vol. 27, no. 10, pp. 3063-3068, 2015.

[36] M. Kargarfard, E. T. C. Lam, A. Shariat et al., "Effects of endurance and high intensity training on ICAM-1 and VCAM-1 levels and arterial pressure in obese and normal weight adolescents," The Physician and Sportsmedicine, vol. 44, no. 3, pp. 208-216, 2016.

[37] S. R. Artínez, L. J. C. Ríos, I. M. Tamayo, L. G. Almeida, M. A. López-Gomez, and C. C. Jara, “An after-school, high-intensity, interval physical activity programme improves health-related fitness in children," Motriz: Revista de Educação Física, vol. 22, pp. 359-367, 2016.

[38] S. Lazzer, G. Tringali, M. Caccavale, R. De Micheli, L. Abbruzzese, and A. Sartorio, "Effects of high-intensity interval training on physical capacities and substrate oxidation rate in obese adolescents," Journal of Endocrinological Investigation, vol. 40, no. 2, pp. 217-226, 2017.

[39] K. A. Dias, C. B. Ingul, A. E. Tjønna et al., "Effect of highintensity interval training on fitness, fat mass and cardiometabolic biomarkers in children with obesity: a randomised controlled trial," Sports Medicine, vol. 48, no. 3, pp. 733-746, 2018.

[40] A. van Biljon, A. J. McKune, K. D. DuBose, U. Kolanisi, and S. J. Semple, "Do short-term exercise interventions improve cardiometabolic risk factors in children?," The Journal of Pediatrics, vol. 203, pp. 325-329, 2018.

[41] C. Morrissey, D. Montero, C. Raverdy, D. Masson, M. J. Amiot, and A. Vinet, "Effects of exercise intensity on microvascular function in obese adolescents," International Journal of Sports Medicine, vol. 39, no. 6, pp. 450-455, 2018.

[42] N. Cvetković, E. Stojanović, N. Stojiljković, D. Nikolić, A. T. Scanlan, and Z. Milanović, "Exercise training in overweight and obese children: recreational football and high-intensity interval training provide similar benefits to physical fitness," Scandinavian Journal of Medicine \& Science in Sports, vol. 28, Supplement 1, pp. 18-32, 2018.

[43] F. Nugent, T. Comyns, A. Nevill, and G. D. Warrington, "The effects of low-volume, high-intensity training on performance parameters in competitive youth swimmers," International Journal of Sports Physiology \& Performance, vol. 14, no. 2, pp. 203-208, 2019.

[44] A. P. Bacon, R. E. Carter, E. A. Ogle, and M. J. Joyner, "VO2max trainability and high intensity interval training in humans: a meta-analysis," PLoS One, vol. 8, no. 9, article e73182, 2013.

[45] S. A. Costigan, N. Eather, R. C. Plotnikoff, D. R. Taaffe, and D. R. Lubans, "High-intensity interval training for improving health-related fitness in adolescents: a systematic review and meta-analysis," British Journal of Sports Medicine, vol. 49, no. 19, pp. 1253-1261, 2015.

[46] Z. Milanović, G. Sporiš, and M. Weston, "Effectiveness of high-intensity interval training (HIT) and continuous endurance training for $\mathrm{VO} 2 \mathrm{max}$ improvements: a systematic review and meta-analysis of controlled trials," Sports Medicine, vol. 45, no. 10, pp. 1469-1481, 2015.

[47] A. García-Hermoso, A. J. Cerrillo-Urbina, T. Herrera-Valenzuela, C. Cristi-Montero, J. M. Saavedra, and V. Martínez-Vizcaíno, "Is high-intensity interval training more effective on improving cardiometabolic risk and aerobic capacity than other forms of exercise in overweight and obese youth? A 
meta-analysis," Obesity Reviews, vol. 17, no. 6, pp. 531-540, 2016.

[48] D. Thivel, J. Masurier, G. Baquet et al., "High-intensity interval training in overweight and obese children and adolescents: systematic review and meta-analysis," The Journal of Sports Medicine and Physical Fitness, vol. 59, no. 2, pp. 310-324, 2019.

[49] J. E. Depiazzi, R. A. Forbes, N. Gibson et al., "The effect of aquatic high-intensity interval training on aerobic performance, strength and body composition in a non-athletic population: systematic review and meta-analysis," Clinical Rehabilitation, vol. 33, no. 2, pp. 157-170, 2019.

[50] D. E. Kristensen, P. H. Albers, C. Prats, O. Baba, J. B. Birk, and J. F. Wojtaszewski, "Human muscle fibre type-specific regulation of AMPK and downstream targets by exercise," The Journal of Physiology, vol. 593, no. 8, pp. 2053-2069, 2015.

[51] S. Larsen, J. Nielsen, C. N. Hansen et al., "Biomarkers of mitochondrial content in skeletal muscle of healthy young human subjects," Journal of Physiology, vol. 590, no. 14, pp. 33493360, 2012.

[52] J. Helgerud, K. Høydal, E. Wang et al., “Aerobic high-intensity intervals improve VO2max more than moderate training," Medicine \& Science in Sports \& Exercise, vol. 39, no. 4, pp. 665-671, 2007.

[53] F. H. Bækkerud, F. Solberg, I. M. Leinan, U. Wisløff, T. Karlsen, and $\varnothing$. Rognmo, "Comparison of three popular exercise modalities on $\mathrm{V}^{\cdot} \mathrm{O} 2 \mathrm{max}$ in overweight and obese," Medicine and Science in Sports and Exercise, vol. 48, no. 3, pp. 491-498, 2016.

[54] F. N. Daussin, J. Zoll, S. P. Dufour et al., "Effect of interval versus continuous training on cardiorespiratory and mitochondrial functions: relationship to aerobic performance improvements in sedentary subjects," American Journal of Physiology-Regulatory, Integrative and Comparative Physiology, vol. 295, no. 1, pp. R264-R272, 2008. 